OPEN ACCESS

Edited by:

Ewald Moser

Medical University of Vienna, Austria

Reviewed by:

Adam Thomas Eggebrecht,

Washington University School of

Medicine, USA

Michael Stuart Patterson,

Juravinski Cancer Centre, Canada

*Correspondence:

Jonathan F. Lovell,

Department of Biomedical

Engineering, University at Buffalo,

State University of New York, 201

Bonner Hall, Buffalo, NY 14260, USA

jflovell@buffalo.edu

Specialty section:

This article was submitted to

Biomedical Physics, a section of the

journal Frontiers in Physics

Received: 26 November 2014

Accepted: 26 March 2015

Published: 10 April 2015

Citation:

Huang H, Song W, Rieffel J and Lovell JF (2015) Emerging applications of

porphyrins in photomedicine.

Front. Phys. 3:23.

doi: 10.3389/fphy.2015.00023

\section{Emerging applications of porphyrins in photomedicine}

\author{
Haoyuan Huang, Wentao Song, James Rieffel and Jonathan F. Lovell * \\ Department of Biomedical Engineering, University at Buffalo, State University of New York, Buffalo, NY, USA
}

Biomedical applications of porphyrins and related molecules have been extensively pursued in the context of photodynamic therapy. Recent advances in nanoscale engineering have opened the door for new ways that porphyrins stand to potentially benefit human health. Metalloporphyrins are inherently suitable for many types of medical imaging and therapy. Traditional nanocarriers such as liposomes, dendrimers and silica nanoparticles have been explored for photosensitizer delivery. Concurrently, entirely new classes of porphyrin nanostructures are being developed, such as smart materials that are activated by specific biochemicals encountered at disease sites. Techniques have been developed that improve treatments by combining biomaterials with photosensitizers and functional moieties such as peptides, DNA and antibodies. Compared to simpler structures, these more complex and functional designs can potentially decrease side effects and lead to safer and more efficient phototherapies. This review examines recent research on porphyrin-derived materials in multimodal imaging, drug delivery, bio-sensing, phototherapy and probe design, demonstrating their bright future for biomedical applications.

Keywords: porphyrins, photodynamic therapy, drug delivery, multimodal imaging, photodynamic molecular beacons, oxygen sensing, metal chelation, porphysomes

\section{Introduction}

The red color of heme in blood has served as a marker for injury for hundreds of millions of years, establishing a fundamental role for porphyrins in medical diagnosis [1]. Heme also serves as the principal imaging contrast agent for functional magnetic resonance imaging (fMRI). The change from diamagnetic oxyhemoglobin to paramagnetic deoxyhemoglobin can be imaged for interpretation of neural activity based on blood oxygenation $[2,3]$. In the past decade, theranostic medical techniques combining imaging and therapy have seen a rapid expansion [4]. Porphyrins and related compounds, with their inherent theranostic optical activity, hold potential for these techniques [5].

Five classes of tetrapyrrole structures are shown in Figure 1A [6]. Porphyrin macrocycles contain of four pyrrole subunits linked together via methine bridges. Reduction of one or two double bonds yields chlorins and bacteriochlorins, respectively. Phthalocyanine and naphthalocyanine contain one or two additional outer cyclohexadiene rings attached to the pyrrole groups, respectively. Typical absorbance spectra of these five tetrapyrroles are shown in Figure 1B. The porphyrin spectrum contains one intense Soret band and multiple Q-bands. For even modest light penetration into biological tissues, excitation of porphyrin Q-bands is required since light with near infrared (NIR) wavelengths can penetrate tissue deeper than shorter wavelength light. However, the absorption of porphyrins at long wavelengths is limited. The other classes of tetrapyrroles provide much higher absorption coefficients in the NIR. 


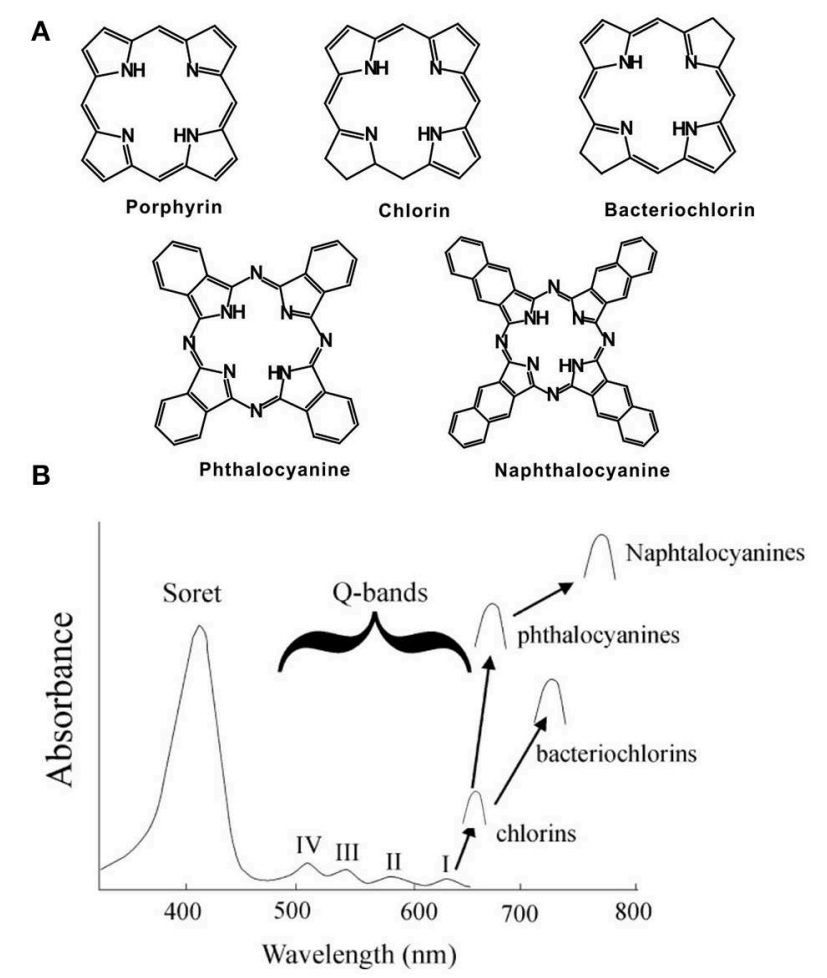

FIGURE 1 | (A) Structure and (B) Absorption of typical porphyrins, chlorins, bacteriochlorins, phthalocyanine and naphthalocyanines. Arrows show Q-band absorption (Adapted with permission from Berg et al. [6]).
Porphyrins can be simply solubilized in water or surfactants, administered intravenously and a target area can be irradiated as is performed in traditional photodynamic therapy (PDT) [7]. However, many types of drug carriers and nanoscale designs can be used together with porphyrins for a variety of applications in imaging and therapy. Porphyrins themselves can actively form a building block in carrier systems. Also, with rational design, porphyrin biomaterials can function like stimuli-responsive smart drugs. These materials fit a broad range of diagnostic and therapeutic applications as shown in Figure 2, and will be discussed throughout this review.

Numerous porphyrin-based photosensitizers have received clinical approval or have entered clinical trials, and these have been reviewed extensively in the literature [7, 23-27]. Undesired sunlight photosensitivity, poor light absorption in deep tissues, and off-target damage to other bystander tissues have led to sustained efforts in the development of improved photosensitizers. Porphyrins were first approved clinically for cancer treatment with Photofrin in 1993 for treatment of bladder cancer [7]. Subsequently, chlorins have been increasingly used as photosensitizers due to their enhanced Q-band absorption. Numerous therapeutic commercial formulations have become available for a range of clinical applications, as shown in Table 1 [28-33]. This steady stream of new PDT compounds illustrates the inherent biocompatibility of porphyrins and their efficacy as photosensitizers.
The fundamental goal in PDT is to oxidize cellular biomolecules via singlet oxygen, thereby inducing cell damage and death [34]. The principal cytotoxic agent, singlet oxygen $\left({ }^{1} \mathrm{O}_{2}\right)$, is generated by energy transfer from photosensitizers to molecular oxygen $\left(\mathrm{O}_{2}\right)$ [35]. The method for the production of ${ }^{1} \mathrm{O}_{2}$ in tissues requires oxygen, light of an appropriate wavelength, and a photosensitizer. The excitation of the sensitizer is achieved via an absorbed photon transition between the ground state $S_{0}$ and a singlet excited state $S_{n}$. The lowest excited singlet state of the sensitizer $S_{1}$ is from relaxation of the $S_{n}$ state. The sensitizer triplet state $\left(T_{1}\right)$ occurs following intersystem crossing. The triplet state lifetime is longer than that of the $S_{1}$ state and it is the excited triplet that can damage the cell by one of two ways; type I or type II mechanisms [36].

In type I mechanisms, the photosensitizer may directly react with a biological substrate via radical formation. The free radicals or radical ions are usually produced by interaction of the triplet sensitizer with a reducing substrate. Scenarios which will produce radicals include the insertion of oxygen or electron transfer to oxygen, electron or hydrogen abstraction from other substrates, initiation of free radical autoxidation, and back electron transfer relations [37]. In type II processes, the triplet state photosensitizer interacts with ground state molecular oxygen $\left({ }^{3} \mathrm{O}_{2}\right)$ first to produce highly reactive ${ }^{1} \mathrm{O}_{2}$, which proceeds to attack cellular targets. This specificity allows examination of the potential roles of ${ }^{1} \mathrm{O}_{2}$ in cellular systems. Type II processes are generally considered most relevant to current PDT practice.

\section{Applications of Metalloporphyrins}

Due to its unique structure comprised of delocalized $\pi$-electrons within a tetrapyrollic skeleton, porphyrins and related molecules not only are intensely colorful, but can also chelate a vast number of metal ions. Extensive inorganic coordination chemistry research involving porphyrins has shown that dozens of elements from the periodic table can be chelated into the center of the macrocycle (e.g., $\mathrm{Li}, \mathrm{Be}, \mathrm{Na}, \mathrm{Mg}, \mathrm{Al}, \mathrm{K}, \mathrm{Ti}, \mathrm{Mn}, \mathrm{Cu}, \mathrm{Co}, \mathrm{Fe}$, $\mathrm{Pt}, \mathrm{Tm}, \mathrm{Yb}$, and $\mathrm{Lu}$ ) [1]. Investigations into metalloporphyrins for diverse catalytic functions have been explored extensively [38-40]. Different metalloporphyrins are capable of providing imaging contrast for near infrared (NIR) fluorescence, magnetic resonance imaging (MRI), X-ray computed tomography (CT), and emerging modalities like photoacoustic imaging. Because of their potential applications in these diagnostic techniques, the study of metalloporphyrins remains active. Different metal selection allows for control of the photochemical and electrochemical properties.

Among metalloporphyrin derivatives, palladium and platinum-chelated porphyrins are attractive photosensitizers for their high singlet oxygen yields and their capacity for oxygen sensing [41, 42]. Due to the sensitivity of their phosphorescence to molecular oxygen, $\mathrm{Pd}(\mathrm{II})$ - and $\mathrm{Pt}(\mathrm{II})$ - porphyrins have become important probes for in vitro $[43,44]$ and in vivo oxygen detection [45-47]. Moreover, their long-lived NIR phosphorescence lifetimes can help reduce background from shorter lifetime auto-fluorescence effects from surrounding tissue. In 1995, Vinogradov et al. found several Pd-chelated porphyrins which 


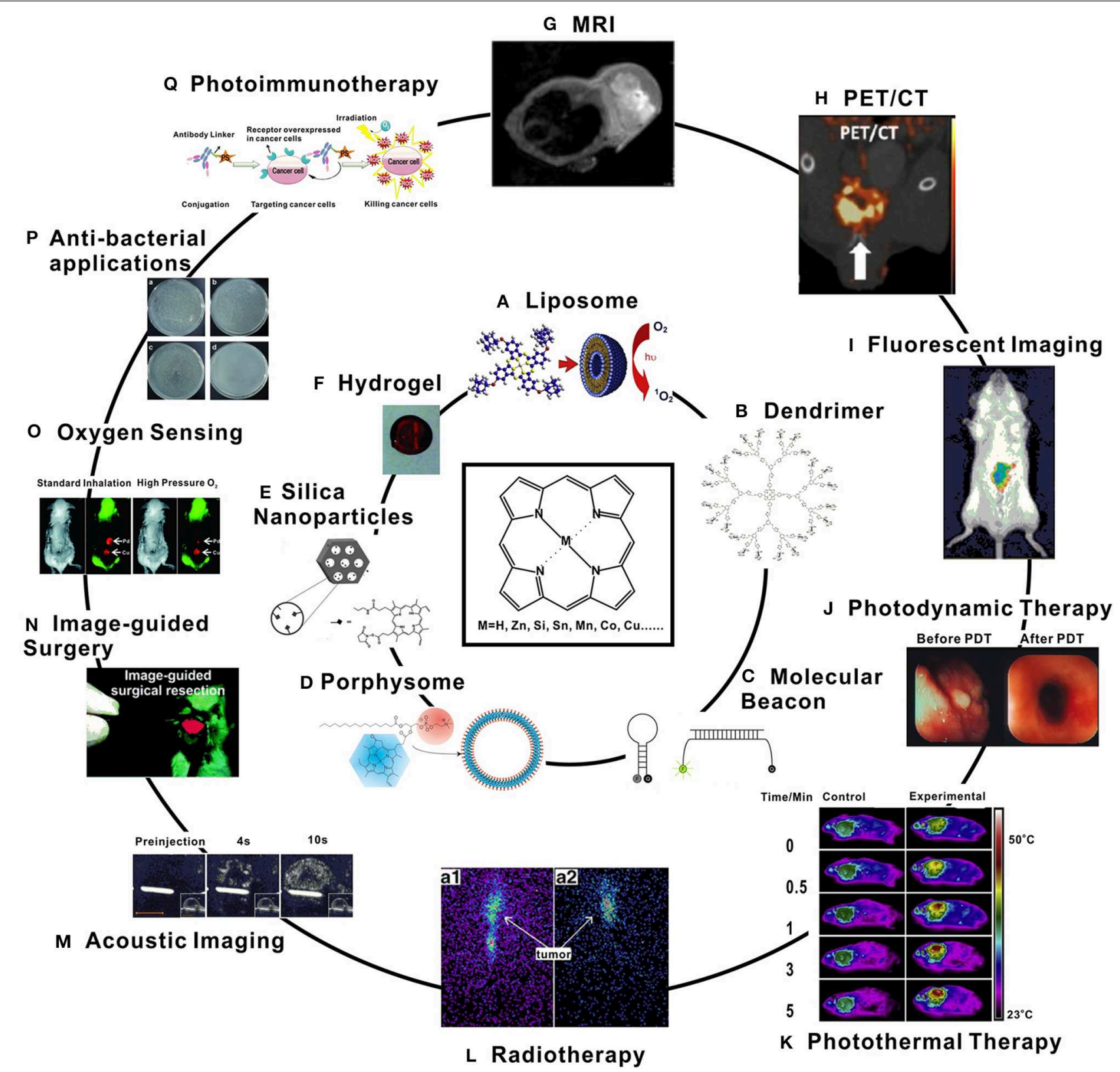

FIGURE 2 | Examples of porphyrin-based biomaterials (inner circle) and applications (outer circle). (A) Liposomal phthalocyanine delivery [8]; (B) Glycoporphyrin dendrimers [9]; (C) Photodynamic molecular beacons [10]; (D) Porphyrin-phospholipid porphysome. [11]; (E) PpIX-modified mesoporous silica nanoparticle [12]; (F) Pd-porphyrin cross-linked hydrogel [13]; (G) In vivo MRI image of Mn-porphyrin nanoparticles [14]; (H) microPET/CT image of orthotopic PC3 tumor model after injection with ${ }^{64} \mathrm{Cu}$-porphysomes [15]; (I) Fluorescence tracking of macrophages after injection of porphyrin-modified nanoparticles [16]; (J) Human esophageal cancer treated with PDT [17];
(K) Thermal images of tumor-bearing mice with Pc-loaded nanoparticles exposed to a NIR laser [18]; (L) $8 \mathrm{~h}$ (a1) and $24 \mathrm{~h}$ (a2) radioimaging of melanoma-bearing mice after injection with ${ }^{188} \mathrm{Re}^{-T_{3,4}} \mathrm{CPP}$ [1]; (M) Acoustic images of a tumor-bearing mouse after injection with porphyrin-shell microbubbles [19]; (N) Image-guided surgery with a porphyrin-PEG cross-linked hydrogel [20]; (O) Phosphorescence images of an implanted $\mathrm{Pd}$-porphyrin hydrogel in mice breathing different oxygen levels [13]; (P) Photoirradiation of bacteria under various photosensitizer conditions [21]; (Q) Photoimmunotherapy concept [22]. All figures used with permission from the indicated references. showed high sensitivity to oxygen concentration changes [48]. Subsequently, numerous formulations of phosphorescent probes have been developed involving copolymers [49], nanoparticles [50-52], dendrimers [53-55], and hydrogels [13, 56].
Besides oxygen sensing, $\mathrm{Pd}(\mathrm{II})$ - and $\mathrm{Pt}(\mathrm{II})$-porphyrins are effective PDT agents. Cheng et al. embedded Pd-meso-tetra (4-carboxylphenyl) porphyrin onto the nano-channel surface of mesoporous silica nanoparticles through amido bonds [57]. 
TABLE 1 | Selected clinical photosensitizers.

\begin{tabular}{|c|c|c|c|}
\hline Name & Q-band absorption (nm) & Applications & Clinical status \\
\hline Photofrin (porfimer sodium) & 630 & $\begin{array}{l}\text { Endobronchial lesions; esophageal cancers; bladder cancer; } \\
\text { gastric and cervical cancers }\end{array}$ & FDA approved \\
\hline Protoporphyrin IX & 635 & $\begin{array}{l}\text { Actinic keratosis; basal-cell cancer; head and neck tumors; } \\
\text { bladder cancers and Bowen's diseases }\end{array}$ & $\begin{array}{l}\text { FDA approved with ALA induced } \\
\text { by Levulan, Hexvix, Cysview, and } \\
\text { Metvixia }\end{array}$ \\
\hline Foscan (temoporfin) & 652 & $\begin{array}{l}\text { Head and neck cancer; prostate and pancreatic tumors; } \\
\text { cutaneous lesions }\end{array}$ & Approved in Europe \\
\hline Purlytin $\left(\mathrm{SnE} \mathrm{T}_{2}\right)$ & 660 & $\begin{array}{l}\text { Cutaneous metastatic breast cancer; basal-cell carcinoma; } \\
\text { Kaposi's sarcoma and prostate cancer }\end{array}$ & Clinical trials (Phase II) \\
\hline $\mathrm{HPPH}$ & 665 & $\begin{array}{l}\text { Basal cell carcinoma; early esophageal cancers and non-small cell } \\
\text { lung cancers }\end{array}$ & Clinical trials (Phase II) \\
\hline Silicon phthalocyanine Pc 4 & 670 & $\begin{array}{l}\text { Skin cancers; actinic keratosis; Bowen's disease and T-cell } \\
\text { non-Hodgkin lymphoma }\end{array}$ & Clinical trials (Phase I) \\
\hline Visudyne (verteporfin) & 690 & $\begin{array}{l}\text { Age-related macular degeneration; choroidal neovascular disease; } \\
\text { pathologic myopia and histoplasmosis }\end{array}$ & FDA approved \\
\hline Motexafin lutetium & 732 & Recurrent breast cancer; cervical, prostate and brain cancers & Clinical trials (Phase II) \\
\hline
\end{tabular}

After incubation with MDA-MB-231 cells, there was significant damage shown in cell morphology following a brief irradiation. Later, similarly structured mesoporous silica nanoparticles were obtained by further surface modification with PEG and RGD molecules [58]. Both the PEG- and RGD- modified nanoparticles showed good efficiency in cellular uptake, bright luminescence, and good PDT efficacy following incubation with cancer cells.

Another unique metal for porphyrin chelation is copper, which has a high chelation affinity for the macrocycle, even in mild aqueous reaction conditions. As shown in Figure 3, Shi et al. reported ${ }^{64} \mathrm{Cu}$ porphyrin radiolabeling in a multifunctional chelator complex [59]. This complex served as an optical imaging probe, a PDT agent, and a PET imaging probe. A pharmacokinetic-modifying linker was used to enhance the water solubility of the porphyrin-peptide-folate (PPF) probe. Folate is a well-established metabolite that can be used to effectively improve cancer targeting specificity [60]. Mice were first injected with ${ }^{64} \mathrm{Cu}$-labeled PPF and analysis showed the stability of the ${ }^{64} \mathrm{Cu}$ labeled metalloporphyrin complex. Micro CT and micro PET imaging were then performed 4 and $24 \mathrm{~h}$ post-injection and the tumor was easily identified with PET.

Zhang et al. recently reported medical imaging applications of naphthalocyanines and spectrally-shifted metallonaphthalocyanines. Dyes were encapsulated with pluronic F127 by drop wise addition of the naphthalocyanines (Nc) into a 10\% Pluronic F127 solution to form a micelle structure of nanoformulated naphthalocyanine, termed nanonaps [61]. After removal of excess surfactant, a dye to surfactant molar ratio of greater than 3 was determined. Nanonaps exhibited stability in the harsh conditions of the stomach and intestine and the particles were fully excreted in feces. Nanonaps exhibited strong photoacoustic signal generation capabilities. In vivo, the photoacoustic signal could penetrate about $2.4 \mathrm{~cm}$ deep though tissue and the movement of nanonaps could clearly be visualized in the intestine. Nanonaps could also be labeled with ${ }^{64} \mathrm{Cu}$ for complementary whole-body PET imaging.

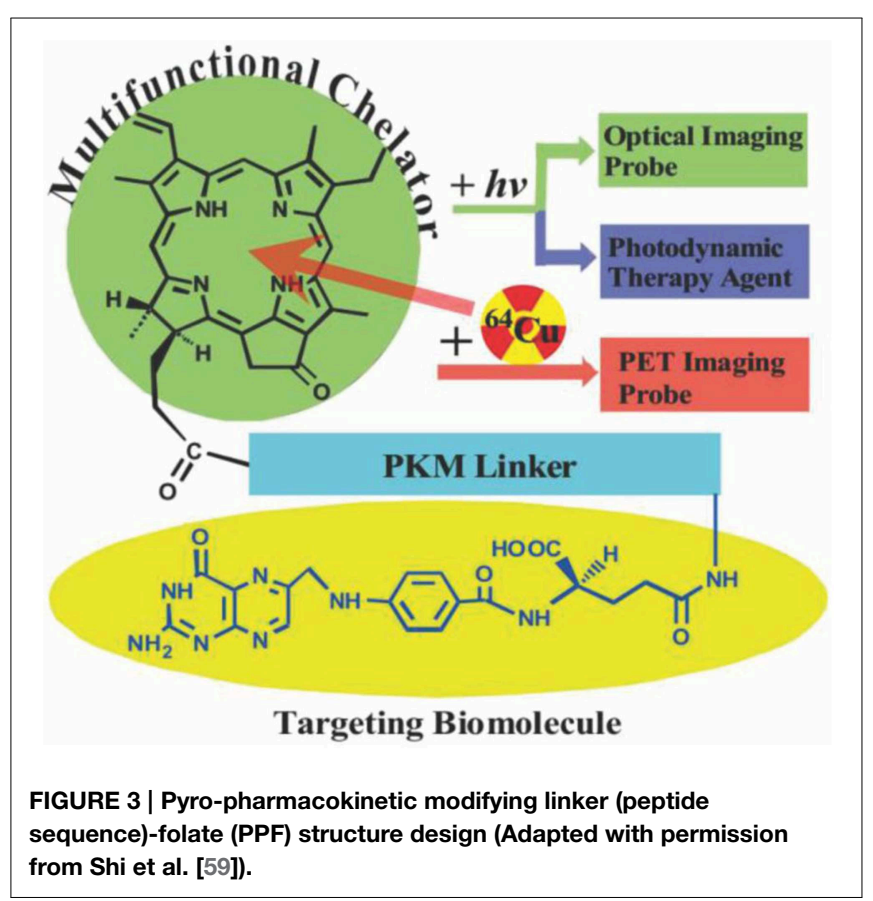

Magnetic metals have also successfully been chelated in porphyrins, offering MRI contrast enhancing capabilities. Mn(III) can be used for medical imaging, but can be toxic when used in high concentrations. However, porphyrins can stably chelate the metal to inhibit unwanted toxicity from large doses [62]. Cheng et al. reported complementary chemical strategies to overcome the limitations of Mn-porphyrin and enhance biocompatibility, pharmacokinetics, and high-field $\mathrm{T}_{1}$ MRI properties [63]. The first strategy was based on Mn meso-tetra (4-sulfonatophenyl) porphyrin, which is capable of providing contrast at high magnetic field strengths, unlike common Gd contrast agents. They found that by varying the size of these Mn-porphyrins they 
could tune the speed of clearance from the body. Two similar derivatives of the Mn meso-tetra (4-sulfonatophenyl) porphyrin were tested following intravenous injection in mice. They found that the smaller and polar type of Mn-porphyrin accumulated in the kidneys and bladder within $10 \mathrm{~min}$, validated by whole body MRI. The signal disappeared after $24 \mathrm{~h}$ post-injection and clearance was confirmed by urine analysis. The renal clearance profile of the larger Mn-porphyrin was significantly slower, demonstrating the ability to tune pharmacokinetics to fit different applications.

\section{Photodynamic Molecular Beacons}

It is possible to build additional layers of control onto PDT photosensitizers, based on activation following recognition of specific biomolecules or biological conditions. These so-called activatable photosensitizers are a new class of photosensitizers which add a layer of complexity over standard photosensitizers, but also offer opportunity for target-tissue specific imaging and therapy [64]. With appropriate design, a photosensitizer that moves to an excited state following photon absorption can be quenched at several different stages prior to generation of singlet oxygen (Figure 4). This photosensitizer deactivation itself can be modulated by various biomolecules such as proteases or nucleic acids, resulting in photosensitizers that are, ideally, only active in target tissues where those targets are present.

\section{Nucleic-acid Activatable Photosensitizers}

Molecular beacons have become archetypal molecular probes and are powerful tools for detecting nucleic acids with single base precision [65]. Traditional molecular beacons are nucleic acid-based sensors consisting of a single stranded oligonucleotide probe with a loop and stem structure. At each terminus is a dye or quencher that are inactive when proximal. When the target is present, the probe loop opens up to form a two-stranded duplex, resulting in separation of the fluorophore and quencher and an increased signal.

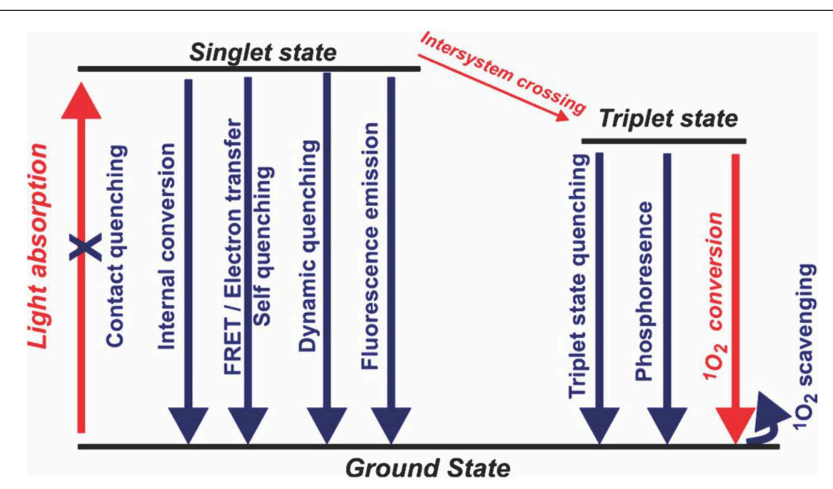

FIGURE 4 | Possible pathways for rational deactivation of an excited state photosensitizer. Simplified singlet oxygen generating diagram with energy levels shown in black and the typical pathway of singlet oxygen generation in red (Adapted with permission from Lovell et al. [64]).
The quencher is responsible for energy capture and transfer from the excited fluorophore [66]. A commonly used quencher is 4-(4-dimethylaminophenylazo) benzoic acid (dabcyl). Dabcyl is a hydrophobic molecule and also a universal quencher for many fluorophores [67]. However, quenching efficiency decreases for dyes emitting longer wavelengths, although alternative quenchers such as gold nanoparticles can be used in certain cases [68]. FRET efficiency can be used to predict the response of photodynamic molecular beacons [69]. Enzymes, nucleic acids, chemical environments and even other photosensitizers are able to activate photodynamic molecular beacons [64, 70, 71].

Nucleic-acid based activatable photosensitizers follow the same design principles as classic molecular beacons except that a photosensitizer is used in lieu of a fluorophore. This principle was first shown in 2008 by Chen et al., who reported a photodynamic molecular beacon (PMB) with tumor specific mRNA-triggered control of singlet oxygen production [72]. The photosensitizer remained silenced in the absence of the nucleic acid target. However, photodynamic activity was restored in the presence of a complementary mRNA sequence.

Lovell et al. enhanced singlet oxygen quenching in the beacon off state by using a so-called linear superquencher consisting of multiple quenching moieties [73]. The construct, with three quenchers, achieved more than 300 fold quenching in the off state. In the presence of targeted DNA in the system, the beacon opened and singlet oxygen production was restored. Due to the hydrophobic structure, this same beacon could partition into lipid-based nanoparticles [74]. Unexpected aggregation was observed in the presence of the target nucleic acid, indicating that photodynamic molecular beacon opening can induce physical perturbations in nanoparticle systems.

Nesterova et al. designed a phthalocyanine (Pc) dimerization based molecular beacon system using phthalocyanines [75]. As shown in Figure 5, the design involved a non-fluorescent $\mathrm{H}$-dimer in the molecular beacon off state. The presence of a complementary DNA sequence caused the formation of a duplex, thereby disrupting the quenching mechanism and restoring fluorescence. This experiment was done with respect to the oligonucleotide chain length. They found that longer oligonucleotide sequences could better restore fluorescence emission. The H-dimer based molecular beacon (Pc2) produced $98 \%$ quenching efficiency with a signal to background ratio of 59.

\section{Enzyme Activatable Photosensitizers}

Enzyme activated photosensitizers are typically quenched until specific enzymatic activity liberates the photosensitizer from a particular quenching environment. In some cases the photosensitizer is tethered via a peptide linker to a quencher, or sometimes the photosensitizer is grafted with peptide linkages onto a polymeric backbone [76, 77]. Whereas most enzymes used for activation have been proteases, other enzymes such as lipases can also be used with appropriately designed photosensitizers [78].

In 2004, Chen et al. reported a photosensitizing beacon design made with a disease-specific linker, a photosensitizer, and a singlet oxygen quencher/scavenger (Figure 6) [79]. In their design, the photosensitizer and singlet oxygen quencher were linked to two ends of a peptide sequence. This design allowed the 

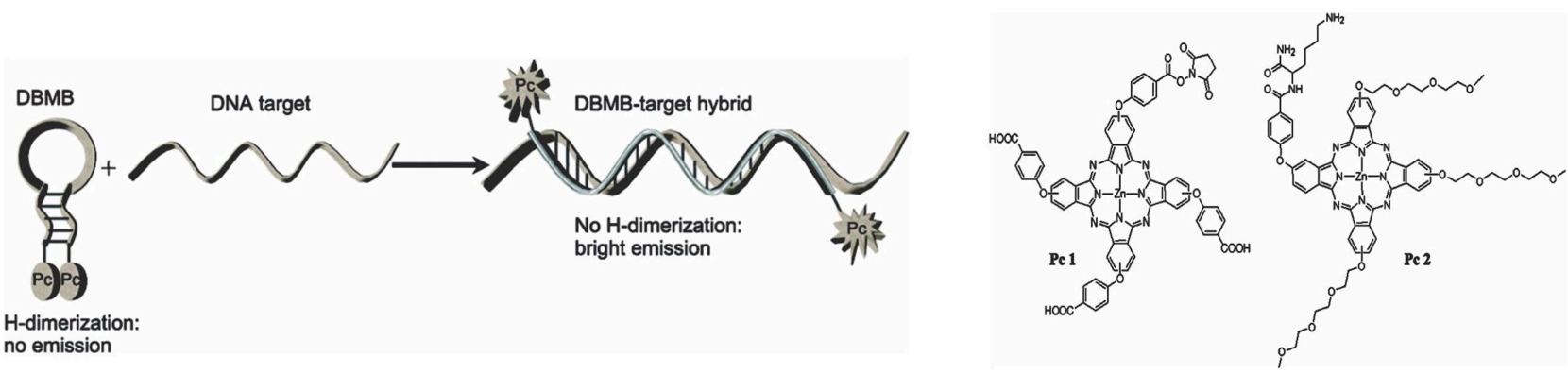

FIGURE 5 | Schematic representation of a dimer based photodynamic molecular beacon is shown on the left and the structure of Pc1 and Pc2 are shown on the right (Adapted with permission from Nesterova et al. [75]).

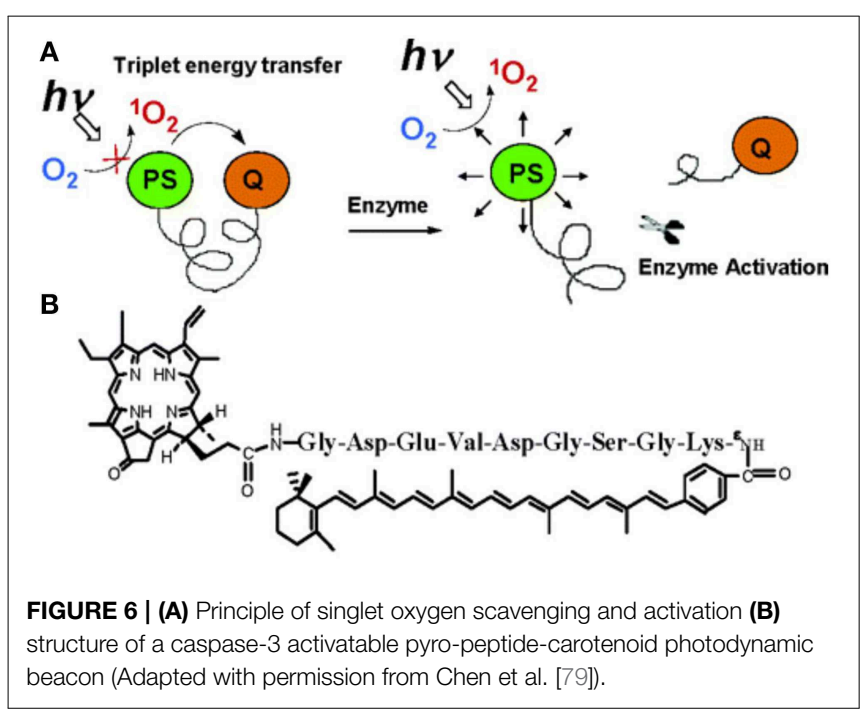

photosensitization to remain quenched in the absence of the specific target molecule [79]. They chose a well-established peptide sequence, cleavable by caspase- 3 , as the substrate [80]. Pyropheophorbide $\alpha$ (pyro) was used as a photosensitizer. The quencher carotenoid was selected to quench and scavenge singlet oxygen [81]. The quencher efficiently decreased singlet oxygen production. The pyro-peptide-carotenoid (PPC) was cleaved when caspase-3 was introduced, resulting in increased singlet oxygen signal. This approach has also been extended to photodynamic beacons that both induce and sense apoptosis [82].

Chen et al. later modified their beacon design using a zipper molecular beacon (ZMB) held together by electrostatic forces of positive and negative peptide residues [83]. They found that enhanced quenching efficiency in the ZMB was the result of both improved fluorescence resonance energy transfer (FRET) effect, and the ground state complex quenching caused by annealing of the dye and quencher through the electrostatic attraction of the zipper arms. A central protease cleavage site allowed for enzyme activation, and the ZMB produced a high signal/background ratio after activation. The ZMB also had the ability to increase the resolution of activated probes and increase the contrast between intact and activated beacons during a cellular uptake experiment.

\section{Nano- and Micro-structured Porphyrin Agents}

The rise of nanomedical engineering has generated interest and improved methodology in designing effective nanoparticulate agents [84]. Porphyrin and its derivatives have been tested in many biological applications along with liposomal delivery, conjugation with biocompatible polymers, or other nanoparticles. These nanomaterials can be functionalized with specific ligands that deliver porphyrins to target areas. Tunable size allows them to effectively reach tumor cells easily through enhanced uptake or direct penetration through cell membranes. These materials work as multifunctional platforms with diagnostic and therapeutic abilities in vitro and in vivo [85].

\section{Porphyrin Dendrimers}

Dendrimers have highly branched three-dimensional architecture with properties that can be precisely controlled and hold promise as nanocarriers [86, 87]. In 1993, dendrimer porphyrins were reported by Jin et al. [88]. The structure of dendrimers shows three critical architecture domains: a multivalent surface, interior shells, and a core. The high density of functional groups on the dendrimer surface makes them a versatile nano-scaffold. The interior core can exhibit host-guest interaction, which mimics micelle structure when host and guest are hydrophobic and hydrophilic molecules respectively [86]. Porphyrin photosensitizers, which are usually hydrophobic, can be attached to the branches or encapsulated in the core [89]. In this way, porphyrins can be made to mimic natural heme-containing proteins. Interestingly, organic reactive groups around porphyrins can be exchanged during the synthesis process, with enough attached in the periphery of dendrimer to create light-harvesting materials [90].

\section{Porphyrin-Containing Liposomes}

Liposomes have been widely used as porphyrin delivery agents [91]. These spherical nanoparticles possess a hollow core that isolates an interior aqueous environment from an exterior one. Liposomes can encapsulate both hydrophobic and hydrophilic materials. Besides disease specific targeting ligands, liposome surfaces have been modified with many organic and inorganic compounds to better accomplish the goal of reduced toxicity and 
increased therapeutic index [92]. Enhancing the biocompatibility or biodegradability of liposomes can be accomplished by a variety of techniques. Modifying lipid composition, surface charge, in vivo or shelf stability, and permeability are just some routes by which this has been achieved [93]. Then, based on the desired properties for each application, the appropriate formulation can be determined. Liposomes injected intravenously are generally taken into the mononuclear phagocytic system. Short blood circulation time generally will decrease delivery efficiency. To overcome this phenomenon, surface modifications like coating with polyethylene glycol (PEG) can help control the clearance time [94]. PEGylated liposomes can be designed for conjugation with antibodies for the combination of long-circulation and targeted delivery [95].

\section{Porphyrin-Phospholipid Compounds}

In 2005, porphyrins were incorporated into polymersome nanovesicles [96]. Later, in 2011 it was determined that by covalently conjugating a porphyrin on a phospholipid side chain, the porphyrin-phospholipid could self-assemble into nanovesicles termed porphysomes, forming a pure porphyrin-bilayer [11]. Porphysomes can be used for diverse biophotonic applications including photothermal therapy and photoacoustic imaging. Porphyrin-phospholipid micelles are also promising theranostic agents [97]. In recent years there has been a push to improve and explore more clinically relevant applications of porphysome technology [98]. Diagnosis and treatment for specific types of cancer has especially driven innovation [99-103].

Because metalloporphyrins possess multifunctional imaging abilities, metallo-porphysomes have been successfully developed for different diagnostic techniques. In 2012, Tam et al. successfully formed stable surface enhanced Raman scattering (SERS) probes by embedding gold nanoparticles into Mn-pyro-lipid porphysomes [104], showing the potential of porphysomes as metal-nanoparticle carriers. Recently, MacDonald et al. used a similar method to generate Mn-pyro-lipid porphysomes for use as MRI contrast agents [105]. The porphyrin lipid was chelated with $\mathrm{Mn}(\mathrm{II})$ as shown in Figure 7. The MRI signal from Mnpyro-lipid porphysomes was comparable to Gd-DTPA, a clinical MRI contrast agent.

Recently, ${ }^{64} \mathrm{Cu}$ porphysomes have been demonstrated for use as in vivo PET imaging agents. In 2012, Liu et al. chose

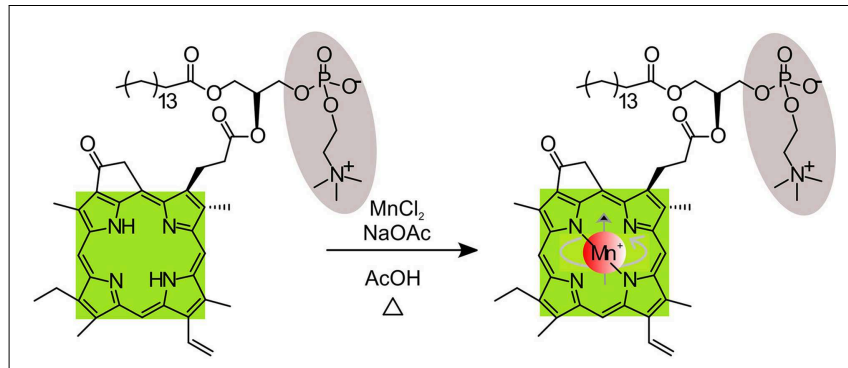

FIGURE 7 | Schematic showing the post chelation process of Mn ion into the pyro-lipid. (Adapted with permission from MacDonald et al. [105]). prostate cancer as a platform to test the PET diagnostic ability of ${ }^{64} \mathrm{Cu}$-porphysomes [106] after labeling them as shown in Figure 8A. $24 \mathrm{~h}$ post injection, ${ }^{64} \mathrm{Cu}$ porphysomes accumulated within prostate tumors and showed a bright PET signal (Figure 8B). They used similarly structured ${ }^{64} \mathrm{Cu}$-porphysomes for further prostate tumor treatment research [15]. After intravenous injection in vivo, the results demonstrated high uptake efficiency and high specificity to PC3 tumors (Figure 8C). Results of ${ }^{64} \mathrm{Cu}$ chelated porphysomes point toward potential clinical translation possibilities.

As opposed to modifications on the porphyrin macrocycle, there are several other modifications that can induce enhanced liposome release. Methods that have already been developed include $\mathrm{pH}$ triggering $[107,108]$, biodegradability $[109,110]$, and thermal sensitivity [111]. These techniques can also be applied to modified porphysomes. In 2012, specific enzyme-biodegradable porphysomes were made by Lovell et al. [112]. By performing side-chain modifications, two similarly structured porphysomes showed significant biodegradable differences. Sn-1 regioisomeric porphysomes remained intact in the liver and spleen, while sn-2 regioisomers showed dramatic degradation. This result illustrates the possibility for controlled porphysome degradation, and the potential for release of contents in specific organs.

More recently, folic acid modified porphysomes were developed by Jin et al. This nanosystem embedded quenched photosensitizers in intact porphysomes and triggered disruption in target cancer cells for PDT under light irradiation [113]. According to the results, a notable difference was observed between cellular uptake efficiency of the nanoparticle with and without the folate acid ligand. After laser treatment, the tumor tissue with folic acid targeted porphysomes was totally destroyed with no reappearance within 14 days.

Porphyrin liposomes can also be used for light-triggered drug delivery applications [114]. Devinyl hexyloxyethypyropheophorbide (HPPH)-conjugated phospholipids were incorporated into nanovesicles that could be permeabilized by NIR-light. Various cargos could be released from the liposomes during NIR irradiation. During liposome formulation, doxorubicin was successfully loaded and released from these nanovesicles, which were shown to re-seal with an intact membrane when no longer exposed to NIR light. These nanovesicles with controlled drug release properties successfully cured nude mice with $\mathrm{KB}$ tumors and exhibited no appearance of regrowth within 90 days. Light-triggered permeabilization of microparticles has also been demonstrated [115].

Recently, a porphyrin-phospholipid-coated upconversion nanoparticle (UCNP) was developed by Rieffel et al. The UCNP (core-shell of $\mathrm{NaYbF}_{4}: \mathrm{Tm}-\mathrm{NaYF}_{4}$ ) was surface modified with PEG- and porphyrin-phospholipid, and also was incubated with ${ }^{64} \mathrm{Cu}$, showing high stability in aqueous system. This nanoparticle probe was shown to enhance signal or contrast in six different imaging techniques including UC imaging, fluorescence, photo acoustic imaging, PET, CT and Cerenkov imaging. The phantom and in vivo data both provide high quality images with this UCNP probe [116].

In addition to the nano-sized spherical porphysomes mentioned above, micro-sized and other structured porphyrin-lipid 


\section{A}
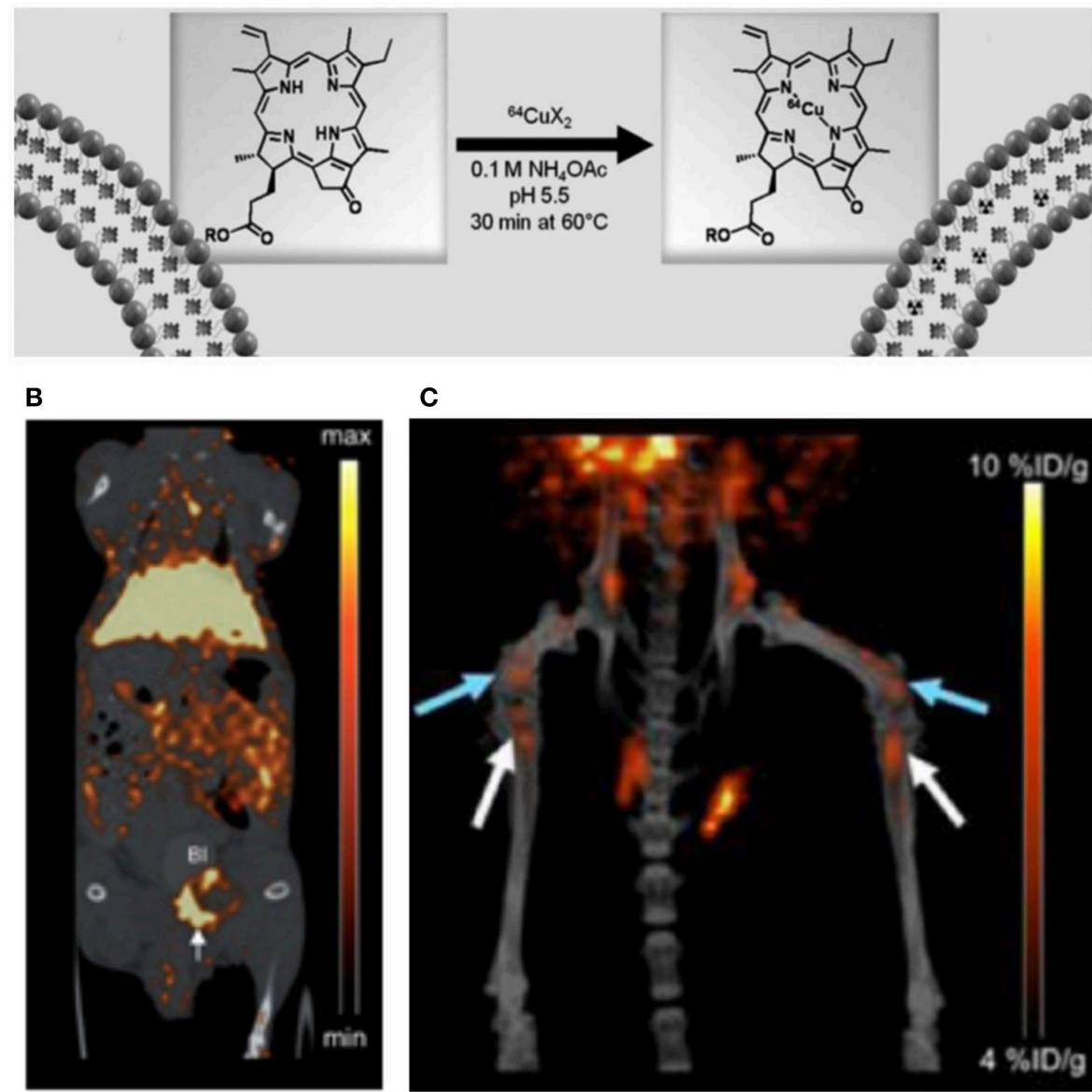

C

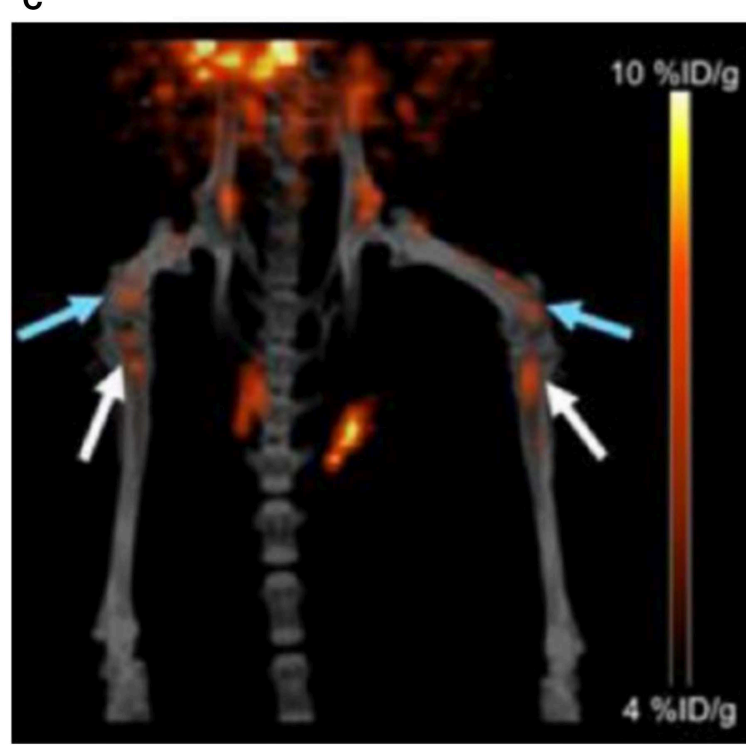

FIGURE 8 | (A) Schematic figure showing the process of chelating ${ }^{64} \mathrm{Cu}$ ion into porphysomes; (B) MicroPET/CT images of coronal single slices through orthotopic PC3 tumor at $24 \mathrm{~h}$ after intravenous injection ${ }^{64} \mathrm{Cu}$-porphysomes;
(C) 3D MicroPET/CT images (blue arrow, distal femur metastases, white arrow, proximal tibia metastases) (Adapted with permission from Liu et al. $[15,106])$.

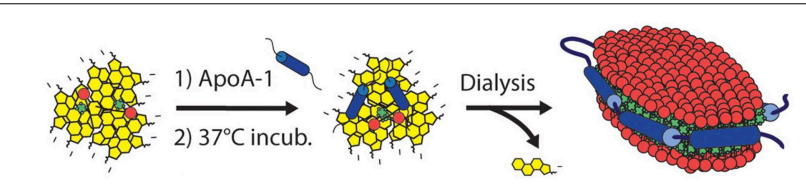

FIGURE 9 | Schematic of the self-assembling process resulting in porphysome nanodics (Adapted with permission from $\mathrm{Ng}$ et al. [117]).

complexes have been developed. One example is the nanodisc formed by ApoA-1 and porphyrin-lipid [117], as shown in Figure 9.

After forming intact nanodiscs, fluorescence and singletoxygen generation were fully quenched. Following enzymatic degradation, the fluorescence and singlet oxygen generation recovered due to disruption of the structure. Another example is porphyrin shell "porshe" microbubbles (Figure 10) [19]. These micromaterials were generated by mixing porphyrin-lipid, phospholipid, polyoxyethylene-40 stearate, phosphate-buffered saline

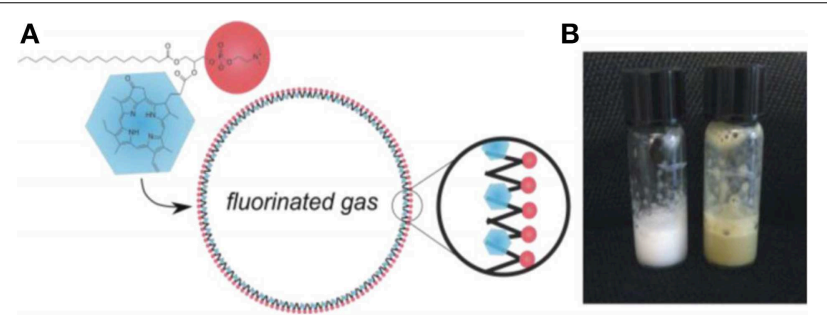

FIGURE 10 | (A) Schematic of the structure of microbubble (B) Photo of microbubbles solutions in room temperature (Adapted with permission from Huynh [19]).

(PBS), and fluorinated gasses together through a mechanical agitation method. Porshe microbubbles were stabilized around $2.7 \mu \mathrm{m}$, creating a large-volume empty cavity. These microbubbles are stiffer than commercial microbubble agents and exhibited photoacoustic and ultrasound signals both in vitro and in vivo. Besides photoacoustic and ultrasound imaging abilities, 
microbubbles also have potential applications working as drug or gene delivery carriers.

\section{Mesoporous Silica-Porphyrin Nanoparticles}

Mesoporous silica nanoparticles are appealing for biomedical applications due to their uniform porosity, ease of functionalization, and biocompatibility [118-120]. Due to their monodispersity, high surface area, and tunable pore size and diameter $[120,121]$, they are being researched as nanocarriers for fluorescence [122], MRI [123-125], drug delivery [126], and PDT $[12,127,128]$ applications. The PDT efficiency of porphyrins is increased by overcoming limitations such as biotoxicity, low solubility in water, and non-specific toxicity following formulation with mesoporous silica nanoparticles.

Research into porphyrin photosensitizers conjugated with mesoporous silica nanoparticles has expanded tremendously in recent years. Many strategies have been employed, one of which is self-assembly of silica-porphyrin conjugates directly [129-133]. These silica-porphyrin molecules can be bonded to other chemical linkers, stimulating the formation of mesoporous nanoparticles. The role of porphyrin in mesoporous silica nanoparticles is to impart imaging capability, act as a photosensitizer, and to chelate metals. In 2010, gold nanorods were encapsulated in the core of porphyrin conjugated mesoporous silica nanoparticles [130]. Besides singlet oxygen generation, these nanoscale materials showed high-contrast two-photon images after being used to treat a MDA-MB-231 human breast adenocarcinoma cell line. In a subsequent study, silicon phthalocyanine molecules were conjugated with mesoporous silica nanoparticles (Pc4SNP) and used for PDT. After light irradiation, A375 and B16F10 melanoma cells incubated with Pc4SNP for $24 \mathrm{~h}$ showed dramatically decreased viability. These nanoparticles were found to be partially internalized into mitochondria and lysosomes [134].

Porphyrins can also be embedded into mesoporous silica nanoparticles. In 2009, a zinc phthalocyanine-loaded mesoporous silica shell was developed by Qian et al. This porphyrinmesoporous silica nanoparticle was active in the NIR, and was shown to kill more than $80 \%$ of murine bladder cancer cells by PDT [135]. In 2012, another method of using zinc phthalocyanine loaded into silica-shell nanoparticles was shown by $\mathrm{Tu}$ et al. [136]. Cell penetration efficiency was increased by cocoating with PEG and polyethyleneimine. Moreover, these silica nanoparticles loaded with zinc phthalocyanine showed bright NIR signals and were implemented as an effective anti-tumor treatment. A new conjugation method was attained through allylisocyanate [133]. The internalization of these nanoparticles in MCF-7 breast cancer cells was observed by confocal microscope imaging, and an efficient PDT response from these porphyrin-silica nanoparticles was demonstrated following laser irradiation.

Porphyrin-conjugated mesoporous silica nanoparticles were recently considered as dual-function drug carriers for delivery to a specific target area. After being conjugated with porphyrin and loaded with anticancer drugs, enhanced anticancer therapy was achieved. In 2011, Wang et al. introduced a dualmode therapeutic multifunctional nanocarrier to deliver doxorubicin to cancer cells [137]. In this study, hollow cubic core and mesoporous shell nanoparticles were made by surface etching of the shell molecules. Isothiocyanate and hematoporphyrin were incorporated into the nanoparticle walls through covalent bonds, acting as fluorescence probes. Doxorubicin molecules were encapsulated into the pores of the nanoparticle. After being incubated with MCF-7 cells, the doxorubicin-nanocage system demonstrated much lower cell viability compared to doxorubicin and nanocages alone. These results indicate this dual-functional nanoparticle can provide enhanced anticancer therapeutic ability and complementary imaging capacity.

\section{Porphyrin Hydrogels}

Hydrogels are three-dimensional networks of hydrophilic polymers capable of containing a large amount of water. Hydrogels have a range of biomedical and pharmaceutical applications, such as in tissue engineering [138-140], drug delivery [141, 142], PDT [143], and photodynamic antimicrobial chemotherapy [144, 145].

Photodynamic antimicrobial chemotherapy (PACT) is a form of PDT that uses light sensitizing drugs to kill microorganisms. Because of the flexibility of hydrogels during the formation process, they can be molded to different shapes appropriate for different clinical conditions, usually around a surgical wound. After surgery for example, the oxygen concentrations around the wound and subcutaneous conditions could be monitored through clinical imaging techniques. The porphyrin photosensitizers can also generate singlet oxygen causing damage to microorganisms, attaining the PACT goal.

Porphyrins and phthalocyanines have been explored as agents to attenuate microbial growth for decades [146]. In 2009, Donnelly et al. used a cross-linked poly (vinyl alcohol) hydrogel loaded with two photosensitizers, methylene blue and meso-tetra (N-methyl-4-pyridyl) porphine tetra tosylate, for antibacterial infection treatment [144]. In the same year, a porphyrin surface modified hydrogel was developed by Parsons et al. for the prevention of intraocular lens-associated infectious endophthalmitis [147]. Cationic tetrakis (4-N-methylpyridyl) porphyrin interacted electrostatically with anionic HEMA (2(hydroxyethyl) methacrylate) and methacrylic acid and a promising antimicrobial reduction in adherence of $S$. epidermidis was shown.

Due to the high biocompatibility and stability of hydrogels, they can stay in a subcutaneous position around wounds for a long period without any side effects. The native imaging abilities of porphyrins provide a non-invasive way to monitor implanted hydrogel within tissues. Lovell et al. cross-linked meso-tetrakis (4-carboxyphenyl) porphine with diamine-functionalized PEGs [20]. After implantation in vivo, the hydrogel showed a detectable fluorescent signal in the subcutaneous position for 2 months and there were no side effects during or after removing the hydrogel. In 2014, a thermosensitive porphyrin-incorporated polycaprolactone (PCL)-PEG hydrogel was developed [148]. This PORPCL-PEG hydrogel maintained a liquid sol state at room temperature, but after subcutaneous injection, the body temperature stimulated the liquid formation of a sol gel, which transformed to a solid hydrogel within 1 day. Within 9 days, the hydrogel degraded and most of it remained close to the injected position. 
A very small amount migrated to other organs but no damage signs were apparent in these organs, demonstrating excellent biocompatibility.

\section{Other Emerging Porphyrin Applications}

Photothermal therapy (PTT) is another type of anti-cancer treatment being explored. Being similar to PDT with respect to light delivery to biological tissues, a photosensitizer can be used to enhance heating and to ablate tumors. To achieve a higher therapeutic efficiency, researchers have also combined PDT and PTT agents. In 2011, Jang et al. combined Al (III) phthalocyanine chloride tetrasulfonic acid $\left(\mathrm{AlPcS}_{4}\right)$ with gold nanorods. By excitation with a $810 \mathrm{~nm}$ laser, the temperature around the tumor tissue increased to $65^{\circ} \mathrm{C}$ [149]. Phthalocyanines and metallo-naphthalocyanines have successfully been delivered in vivo through polymerization or combination with common nano-carriers $[18,150,151]$. After injection into mice, all of the subjects showed large temperature increases with laser stimulation, and demonstrated high levels of anti-tumor efficacy. In 2013, Jin et al. used porphysomes as PTT agents. After exposure to the laser for only $85 \mathrm{~s}$, the temperature around tumors reached more than $60^{\circ} \mathrm{C}$. Also, compared to the commercial PDT agent Photofrin, these PTT agents showed high therapeutic ability under both acute hypoxic and hyperoxic conditions, while Photofrin could only cure the tumors under hyperoxic conditions [101].

Two-photon imaging uses photons with half the energy of the corresponding one-photon transition and due to their intrinsic imaging ability, many porphyrin agents have been explored as two-photon probes [152]. Porphyrin dimers present unique imaging properties [153-155], as do electrostatic assemblies comprised of porphyrin and polymers [156]. In 2010, Poon et al. synthesized an amphiphilic ruthenium (II)-polypyridl porphyrin complex. Besides the higher cell uptake efficiency after incubation with human nasopharyngeal carcinoma HK-1 cells, this $\mathrm{Ru}$-porphyrin complex also demonstrated high red fluorescence intensity after excitation with a $800 \mathrm{~nm}$ laser [157]. In the same year, Sakadzic et al. used Pd-porphyrins encapsulated in poly (arylglycine) dendrimers as a two-photon-enhanced phosphorescent probe for detecting oxygen levels. The probes showed a strong phosphorescence signal in microvasculature up to $250 \mu \mathrm{m}$ deep below the cortical surface, overcoming the low two-photon signals seen when using other oxygen phosphorescence probes [45]. Porphyrin nanoparticles have also been used for twophoton applications [158].

Targeted PDT involving porphyrins has been explored extensively and continues to attract interest. Conjugation of photosensitizers to antibodies has been explored for decades for photoimmunotherapy (PIT) [159]. As opposed to traditional passive targeting methods, photosensitizers can actively target diseased tissues through covalent binding with antibodies or antibody fragments. The antibodies chosen to decorate delivery vehicles have the ability to bind with cancer-tissue associated antigens. MAbs usually play the role of blocking specific receptor signaling pathways in cells, or as vectors to deliver porphyrins into target cancer cells [160]. Various types of antibodies have been used including intact IgG, and single chain fragments (scFV) successfully bind with porphyrin-based photosensitizers. This formulation of photodynamic agents has progressed well in treatment of diseases such as ovarian cancer [160], human colon carcinoma [161], L-M fibroblasts [162], and human breast carcinoma [162]. In 1983, Mew et al. combined hematoporphyrin with anti-M-1 to treat DBA/2J myosarcoma M-1 in mice. Their conjugates killed $95 \%$ of tumor cells in vitro and restrained tumor growth after injection into mice [163]. Later, Goff et al. used chlorin derivative, CMA, conjugated with anti-ovarian carcinoma monoclonal antibody OC125. After incubation with cells for $1 \mathrm{~h}$ and irradiation with a $654 \mathrm{~nm}$ laser, the PIT agent shown obvious selectivity to ovarian cells compared to other non-ovarian cells [164]. Furthermore, in 2005, Hudson et al. utilized two porphyrin isothiocyanates (one is neutral and one is positive charged) for facile conjugation with internalizing MAb FSP 77 and 17.1A, and noninternalizing MAb 35A7. Based on their results, all the conjugates demonstrated increased efficiency compared to free photosensitizers with the internalizing conjugates performing better than non-internalizing variants. Also, comparing to the two photosensitizers, the cationic agent shown shorter serum half-life and a high loading ratio [165]. In 2011, conjugation of trastuzumab or panitumumab (which are against human epidermal growth factor HER1 and HER2) with the phthalocyanine-based dye IR700 was performed. Each $\mathrm{mAb}$ combined with approximately three dyes. Trastuzumab-IR700 fluorescence signals were detected on the cell surface and internally after incubation with 3T3-HER2 cells for 1 and $6 \mathrm{~h}$, respectively, and induced cellular death after laser irradiation. The same result was observed after incubating Panitumumab-IR700 with HER1-positive A431 cells. Also, in vitro data showed phototoxicity of $\mathrm{mAb}-\mathrm{IR} 700$ conjugations only to the target cells. After injection into mice, both $\mathrm{mAb}$ IR700 conjugations demonstrated target-specific accumulation; and with treatment 1 day post-injection, both conjugations led to significant tumor shrinkage [166]. During the treatment of A431 cancer with Panitumumab-IR700, Mitsunaga et al. found repeated exposure to light of the target tissue area will lead to enhanced therapeutic efficiency [167]. Recently Kobayashi et al. have been applying this approach to various mouse models of cancer including MDAMB468-luc cells and disseminated peritoneal ovarian cancer have successfully been treated with this approach [168-170]. With advances in antibody production techniques coupled with development of porphyrin-based photosensitizer synthesis, clinical translation of PIT is possible.

Besides PIT, vascular targeted PDT is another approach for anti-cancer therapy [171]. This is accomplished through attacking vascular tissue around tumor sites to generate localized necrosis. The common method for anti-vascular therapy is based on damaging blood vessels, inhibiting formation of de novo neovascularization, and stopping blood flow [172]. In 2004, Brandis et al. developed a hydrophilic bateriochlorophyll derivative compound of Pd-bacteriopheophorbide (Tookad), which has been used in clinical trials as an antivascular agent. Differing from other anti-vascular agents, their molecules showed low aqueous aggregation and high affinity to serum proteins, which could extend the circulation time of these agents and bring them to the vasculature of important target 
organs [173]. In 2014, Reddy et al. used Photofrin combined with iron oxide crystals and polyethylene glycol to form a multifunctional platform that could shrink orthotopic gliomas in rats [174].

\section{Conclusion}

As clinical agents for PDT, porphyrins occupy a central niche in photomedicine. A variety of metalloporphyrin derivatives have been synthesized as probes for diagnostic techniques, such as fluorescence imaging, MRI, PET, and CT. Photodynamic molecular beacons are promising constructs to enhance localized activation of porphyrins for PDT and imaging. Modified liposomes, dendrimers and other nanoparticles serve as carriers to deliver

\section{References}

1. Zhang Y, Lovell JF. Porphyrins as theranostic agents from prehistoric to modern times. Theranostics (2012) 2:905-15. doi: 10.7150/thno.4908

2. Blamire AM, Ogawa S, Ugurbil K, Rothman D, McCarthy G, Ellermann JM, et al. Dynamic mapping of the human visual cortex by high-speed magnetic resonance imaging. Proc Natl Acad Sci USA. (1992) 89:11069-73. doi: 10.1073/pnas.89.22.11069

3. Belliveau JW, Kennedy DN, McKinstry RC, Buchbinder BR, Weisskoff RM, Cohen MS, et al. Functional mapping of the human visual cortex by magnetic resonance imaging. Science (1991) 254:716-9. doi: 10.1126/science.1948051

4. Kelkar SS, Reineke TM. Theranostics: combining imaging and therapy. Bioconjug Chem. (2011) 22:1879-903. doi: 10.1021/bc200151q

5. Josefsen LB, Boyle RW. Unique diagnostic and therapeutic roles of porphyrins and phthalocyanines in photodynamic therapy, imaging and theranostics. Theranostics (2012) 2:916-66. doi: 10.7150/thno.4571

6. Berg K, Selbo PK, Weyergang A, Dietze A, Prasmickaite L, Bonsted A, et al. Porphyrin-related photosensitizers for cancer imaging and therapeutic applications. J Microsc. (2005) 218:133-47. doi: 10.1111/j.1365-2818.2005.01471.x

7. Dougherty TJ, Gomer CJ, Henderson BW, Jori G, Kessel D, Korbelik M, et al. Photodynamic therapy. J Natl Cancer Inst. (1998) 90:889-905. doi: 10.1093/jnci/90.12.889

8. López Zeballos NC, García Vior MC, Awruch J, Dicelio LE. An exhaustive study of a novel sulfur-linked adamantane tetrasubstituted zinc(II) phthalocyanine incorporated into liposomes. J Photochem Photobiol A. (2012) 235:7-13. doi: 10.1016/j.jphotochem.2012.02.022

9. Kushwaha D, Tiwari VK. Click chemistry inspired synthesis of glycoporphyrin dendrimers. J Org Chem. (2013) 78:8184-90. doi: 10.1021/jo4012392

10. Stewart CN Jr. Monitoring the presence and expression of transgenes in living plants. Trends Plant Sci. (2005) 10:3906. doi: 10.1016/j.tplants.2005.06.003

11. Lovell JF, Jin CS, Huynh E, Jin H, Kim C, Rubinstein JL, et al. Porphysome nanovesicles generated by porphyrin bilayers for use as multimodal biophotonic contrast agents. Nat Mater. (2011) 10:324-32. doi: 10.1038/nmat2986

12. Tu H-L, Lin Y-S, Lin H-Y, Hung Y, Lo L-W, Chen Y-F, et al. In vitro studies of functionalized mesoporous silica nanoparticles for photodynamic therapy. Adv Mater (2009) 21:172-7. doi: 10.1002/adma.200800548

13. Huang H, Song W, Chen G, Reynard JM, Ohulchanskyy TY, Prasad PN, et al. Pd-porphyrin-cross-linked implantable hydrogels with oxygenresponsive phosphorescence. Adv Healthc Mater. (2014) 3:891-6. doi: 10.1002/adhm.201300483

14. Jing L, Liang X, Li X, Lin L, Yang Y, Yue X, et al. Mn-porphyrin conjugated au nanoshells encapsulating doxorubicin for potential magnetic resonance imaging and light triggered synergistic therapy of cancer. Theranostics (2014) 4:858-71. doi: 10.7150/thno.8818

15. Liu TW, MacDonald TD, Jin CS, Gold JM, Bristow RG, Wilson BC, et al. Inherently multimodal nanoparticle-driven tracking and real-time delineation of orthotopic prostate tumors and micrometastases. ACS Nano (2013) 7:4221-32. doi: 10.1021/nn400669r porphyrins to the target tissues. Recent porphyrin constructs have begun to be used in multifunctional nano- or micro-carriers, which hold potential to deliver drugs to target tissues with higher efficiency. Porphyrins and related macrocycles provide a large range of possibilities to address almost any diagnostic and therapeutic challenge. More work is still needed to advance recently emerging porphyrin constructs to the clinical stage to fulfill their potential.

\section{Acknowledgments}

This work was made possible with support from the National Institutes of Health (R01EB017270 and DP5OD017898).

16. Hayashi K, Nakamura M, Ishimura K. Silica-porphyrin hybrid nanotubes for in vivo cell tracking by near-infrared fluorescence imaging. Chem Commun. (Camb.) (2012) 48:3830-2. doi: 10.1039/C2CC17444H

17. Pandey RK, Goswami LN, Chen Y, Gryshuk A, Missert JR, Oseroff A, et al. Nature: a rich source for developing multifunctional agents. tumorimaging and photodynamic therapy. Lasers Surg Med. (2006) 38:445-67. doi: 10.1002/lsm.20352

18. Peng J, Zhao L, Zhu X, Sun Y, Feng W, Gao Y, et al. Hollow silica nanoparticles loaded with hydrophobic phthalocyanine for near-infrared photodynamic and photothermal combination therapy. Biomaterials (2013) 34:7905-12. doi: 10.1016/j.biomaterials.2013.07.027

19. Huynh E, Lovell JF, Helfield BL, Jeon M, Kim C, Goertz DE, et al. Porphyrin shell microbubbles with intrinsic ultrasound and photoacoustic properties. $J$ Am Chem Soc. (2012) 134:16464-7. doi: 10.1021/ja305988f

20. Lovell JF, Roxin A, Ng KK, Qi Q, McMullen JD, DaCosta RS, et al. Porphyrin-cross-linked hydrogel for fluorescence-guided monitoring and surgical resection. Biomacromolecules (2011) 12:3115-8. doi: 10.1021/ bm200784s

21. Liu K, Liu Y, Yao Y, Yuan H, Wang S, Wang Z, et al. Supramolecular photosensitizers with enhanced antibacterial efficiency. Angew Chem. (2013) 125:8443-7. doi: 10.1002/ange.201303387

22. Pereira PMR, Korsak B, Sarmento B, Schneider RJ, Fernandes R, Tome JPC. Antibodies armed with photosensitizers: from chemical synthesis to photobiological applications. Org Biomol Chem. (2015) 13:2518-29. doi: 10.1039/C4OB02334J

23. Dolmans DE, Fukumura D, Jain RK. Photodynamic therapy for cancer. Nat Rev Cancer. (2003) 3:380-7. doi: 10.1038/nrc1071

24. Treatment of Age-related Macular Degeneration With Photodynamic Therapy Study G. Photodynamic therapy of subfoveal choroidal neovascularization in age-related macular degeneration with verteporfin: one-year results of 2 randomized clinical trials-tap report 1. Arch Ophthalmol. (1999) 117:1329-45. doi: 10.1001/archopht.117.10.1329

25. Ochsner M. Photophysical and photobiological processes in the photodynamic therapy of tumours. J Photochem Photobiol B. (1997) 39:1-18. doi: 10.1016/S1011-1344(96)07428-3

26. Bonnett R. Photosensitizers of the porphyrin and phthalocyanine series for photodynamic therapy. Chem Soc Rev. (1995) 24:19-33. doi: $10.1039 / \mathrm{cs} 9952400019$

27. Brown SB, Brown EA, Walker I. The present and future role of photodynamic therapy in cancer treatment. Lancet Oncol. (2004) 5:497-508. doi: 10.1016/S1470-2045(04)01529-3

28. Lucky SS, Soo KC, Zhang Y. Nanoparticles in photodynamic therapy. Chem Rev. (2015) 115:1990-2042. doi: 10.1021/cr5004198

29. Huang Z. A review of progress in clinical photodynamic therapy. Technol Cancer Res Treat. (2005) 4:283-93. doi: 10.1177/153303460500 400308

30. Yoon I, Li JZ, Shim YK. Advance in photosensitizers and light delivery for photodynamic therapy. Clin Endosc. (2013) 46:7-23. doi: $10.5946 / \mathrm{ce} .2013 .46 .1 .7$ 
31. Detty MR, Gibson SL, Wagner SJ. Current clinical and preclinical photosensitizers for use in photodynamic therapy. J Med Chem. (2004) 47:3897-915. doi: $10.1021 / \mathrm{jm} 040074 \mathrm{~b}$

32. Allison RR, Downie GH, Cuenca R, Hu X-H, Childs CJH, Sibata CH. Photosensitizers in clinical PDT. Photodiagnosis Photodyn Ther. (2004) 1:27-42. doi: 10.1016/S1572-1000(04)00007-9

33. Ormond AB, Freeman HS. Dye sensitizers for photodynamic therapy. Materials (2013) 6:817-40. doi: 10.3390/ma6030817

34. Celli JP, Spring BQ, Rizvi I, Evans CL, Samkoe KS, Verma S, et al. Imaging and photodynamic therapy: mechanisms, monitoring, and optimization. Chem Rev. (2010) 110:2795-838. doi: 10.1021/cr900300p

35. Schweitzer C, Schmidt R. Physical mechanisms of generation and deactivation of singlet oxygen. Chem Rev. (2003) 103:1685-758. doi: $10.1021 / \mathrm{cr} 010371 \mathrm{~d}$

36. DeRosa MC, Crutchley RJ. Photosensitized singlet oxygen and its applications. Coord Chem Rev. (2002) 233-234:351-71. doi: 10.1016/S00108545(02)00034-6

37. Agnez-Lima LF, Melo JTA, Silva AE, Oliveira AHS, Timoteo ARS, LimaBessa KM, et al. DNA damage by singlet oxygen and cellular protective mechanisms. Mutat Res. (2012) 751:15-28. doi: 10.1016/j.mrrev.2011.12.005

38. Feng D, Gu Z-Y, Li J-R, Jiang H-L, Wei Z, Zhou H-C. Zirconiummetalloporphyrin PCN-222: mesoporous metal-organic frameworks with ultrahigh stability as biomimetic catalysts. Angew Chem. (2012) 124:10453-6. doi: 10.1002/ange.201204475

39. Chen L, Yang Y, Jiang D. CMPs as scaffolds for constructing porous catalytic frameworks: a built-in heterogeneous catalyst with high activity and selectivity based on nanoporous metalloporphyrin polymers. J Am Chem Soc. (2010) 132:9138-43. doi: 10.1021/ja1028556

40. Che C-M, Lo VK-Y, Zhou C-Y, Huang J-S. Selective functionalisation of saturated C-H bonds with metalloporphyrin catalysts. Chem Soc Rev. (2011) 40:1950-75. doi: 10.1039/C0CS00142B

41. Borisov SM, Zenkl G, Klimant I. Phosphorescent Platinum(II) and Palladium(II) complexes with azatetrabenzoporphyrins-new red laser diodecompatible indicators for optical oxygen sensing. ACS Appl Mater Interfaces. (2010) 2:366-74. doi: 10.1021/am900932z

42. Wang X-D, Chen H-X, Zhao Y, Chen X, Wang X-R, Chen X. Optical oxygen sensors move towards colorimetric determination. TrAC Trends Anal Chem. (2010) 29:319-38. doi: 10.1016/j.trac.2010.01.004

43. Ceroni P, Lebedev AY, Marchi E, Yuan M, Esipova TV, Bergamini G, et al. Evaluation of phototoxicity of dendritic porphyrin-based phosphorescent oxygen probes: an in vitro study. Photochem Photobiol Sci. (2011) 10:1056-65. doi: 10.1039/C0PP00356E

44. Koo Lee Y-E, Ulbrich EE, Kim G, Hah H, Strollo C, Fan W, et al. Near infrared luminescent oxygen nanosensors with nanoparticle matrix tailored sensitivity. Anal Chem. (2010) 82:8446-55. doi: 10.1021/ac1015358

45. Sakadzić S, Roussakis E, Yaseen MA, Mandeville ET, Srinivasan VJ, Arai K, et al. Two-photon high-resolution measurement of partial pressure of oxygen in cerebral vasculature and tissue. Nat Methods. (2010) 7:755-9. doi: 10.1038 /nmeth. 1490

46. Lebedev AY, Cheprakov AV, Sakadzić S, Boas DA, Wilson DF, Vinogradov SA. Dendritic phosphorescent probes for oxygen imaging in biological systems. ACS Appl Mater Interfaces. (2009) 1:1292-304. doi: $10.1021 / \mathrm{am} 9001698$

47. Esipova TV, Karagodov A, Miller J, Wilson DF, Busch TM, Vinogradov SA. Two new "Protected" oxyphors for biological oximetry: properties and application in tumor imaging. Anal Chem. (2011) 83:8756-65. doi: 10.1021/ac20 22234

48. Vinogradov SA, Wilson DF. Metallotetrabenzoporphyrins. New phosphorescent probes for oxygen measurements. J Chem Soc Perkin Trans. (1995) 2:103-11. doi: 10.1039/P29950000103

49. Xiang H, Zhou L, Feng Y, Cheng J, Wu D, Zhou X. Tunable fluorescent/phosphorescent platinum(II) porphyrin-fluorene copolymers for ratiometric dual emissive oxygen sensing. Inorg Chem. (2012) 51:5208-12. doi: $10.1021 /$ ic $300040 \mathrm{n}$

50. Cywinski PJ, Moro AJ, Stanca SE, Biskup C, Mohr GJ. Ratiometric porphyrin-based layers and nanoparticles for measuring oxygen in biosamples. Sens Actuators B. (2009) 135:472-7. doi: 10.1016/j.snb.2008.09.039
51. Sung T-W, Lo Y-L. Dual sensing of temperature and oxygen using PtTFPP-doped CdSe/SiO2 core-shell nanoparticles. Sens Actuators B. (2012) 173:406-13. doi: 10.1016/j.snb.2012.07.028

52. Kondrashina AV, Dmitriev RI, Borisov SM, Klimant I, O'Brien I, Nolan YM, et al. A phosphorescent nanoparticle-based probe for sensing and imaging of (Intra) cellular oxygen in multiple detection modalities. Adv Funct Mater. (2012) 22:4931-9. doi: 10.1002/adfm.201201387

53. Dunphy I, Vinogradov SA, Wilson DF. Oxyphor R2 and G2: phosphors for measuring oxygen by oxygen-dependent quenching of phosphorescence. Anal Biochem. (2002) 310:191-8. doi: 10.1016/j.snb.2012.07.028

54. Finikova OS, Lebedev AY, Aprelev A, Troxler T, Gao F, Garnacho C, et al. Oxygen microscopy by two-photon-excited phosphorescence. Chem Phys Chem. (2008) 9:1673-9. doi: 10.1002/cphc.200800296

55. Briñas RP, Troxler T, Hochstrasser RM, Vinogradov SA. Phosphorescent oxygen sensor with dendritic protection and two-photon absorbing antenna. $J$ Am Chem Soc. (2005) 127:11851-62. doi: 10.1021/ja052947c

56. López-Ruiz N, Martínez-Olmos A, Pérez de Vargas-Sansalvador IM, Fernández-Ramos MD, Carvajal MA, Capitan-Vallvey LF, et al. Determination of $\mathrm{O} 2$ using colour sensing from image processing with mobile devices. Sens Actuators B. (2012) 171-172:938-45. doi: 10.1016/j.snb.2012.06.007

57. Cheng S-H, Lee C-H, Yang C-S, Tseng F-G, Mou C-Y, Lo L-W. Mesoporous silica nanoparticles functionalized with an oxygen-sensing probe for cell photodynamic therapy: potential cancer theranostics. J Mater Chem. (2009) 19:1252-7. doi: 10.1039/b816636f

58. Cheng S-H, Lee C-H, Chen M-C, Souris JS, Tseng F-G, Yang C-S, et al. Trifunctionalization of mesoporous silica nanoparticles for comprehensive cancer theranostics-the trio of imaging, targeting and therapy. J Mater Chem. (2010) 20:6149-57. doi: 10.1039/c0jm00645a

59. Shi J, Liu TWB, Chen J, Green D, Jaffray D, Wilson BC, et al. Transforming a targeted porphyrin theranostic agent into a PET imaging probe for cancer. Theranostics (2011) 1:363-70. doi: 10.7150/thno/v01p0363

60. Low PS, Kularatne SA. Folate-targeted therapeutic and imaging agents for cancer. Curr Opin Chem Biol. (2009) 13:256-62. doi: 10.1016/j.cbpa.2009.03.022

61. Zhang Y, Jeon M, Rich LJ, Hong H, Geng J, Zhang Y, et al. Non-invasive multimodal functional imaging of the intestine with frozen micellar naphthalocyanines. Nat Nanotechnol. (2014) 9:631-8. doi: 10.1038/nnano.2014.130

62. Takehara Y, Sakahara H, Masunaga H, Isogai S, Kodaira N, Takeda H, et al. Tumour enhancement with newly developed Mn-metalloporphyrin (HOP9P) in magnetic resonance imaging of mice. Br J Cancer. (2001) 84:1681-5. doi: 10.1054/bjoc.2001.1802

63. Cheng W, Haedicke IE, Nofiele J, Martinez F, Beera K, Scholl TJ, et al. Complementary strategies for developing gd-free high-field T1 MRI contrast agents based on MnIII porphyrins. J Med Chem. (2014) 57:516-20. doi: $10.1021 / \mathrm{jm} 401124 \mathrm{~b}$

64. Lovell JF, Liu TWB, Chen J, Zheng G. Activatable photosensitizers for imaging and therapy. Chem Rev. (2010) 110:2839-57. doi: 10.1021/cr900236h

65. Tyagi S, Kramer FR. Molecular beacons: probes that fluoresce upon hybridization. Nat Biotechnol. (1996) 14:303-8. doi: 10.1038/nbt03 96-303

66. Fabbrizzi L, Licchelli M, Pallavicini P, Sacchi D, Taglietti A. Sensing of transition metals through fluorescence quenching or enhancement. A review. Analyst (1996) 121:1763-8. doi: 10.1039/AN9962101763

67. Tyagi S, Bratu DP, Kramer FR. Multicolor molecular beacons for allele discrimination. Nat Biotechnol. (1998) 16:49-53. doi: 10.1038/nbt0198-49

68. Dubertret B, Calame M, Libchaber AJ. Single-mismatch detection using gold-quenched fluorescent oligonucleotides. Nat Biotechnol. (2001) 19:365-70. doi: 10.1038/86762

69. Lovell JF, Chen J, Jarvi MT, Cao W-G, Allen AD, Liu Y, et al. FRET Quenching of photosensitizer singlet oxygen generation. J Phys Chem B. (2009) 113:3203-11. doi: 10.1021/jp810324v

70. Lovell JF, Zheng G. Activatable smart probes for molecular optical imaging and therapy. I Innov Opt Health Sci. (2008) 1:45-61. doi: $10.1142 /$ S1793545808000157

71. Lou K, Lovell JF. A quenched binuclear ruthenium(II) dimer activated by another photosensitizer. Chem Commun. (Camb.) (2014) 50:3231-3. doi: 10.1039/C3CC49171D 
72. Chen J, Lovell JF, Lo P-C, Stefflova K, Niedre M, Wilson BC, et al. A tumor mRNA-triggered photodynamic molecular beacon based on oligonucleotide hairpin control of singlet oxygen production. Photochem Photobiol Sci. (2008) 7:775-81. doi: 10.1039/B800653A

73. Lovell JF, Chen J, Huynh E, Jarvi MT, Wilson BC, Zheng G. Facile synthesis of advanced photodynamic molecular beacon architectures. Bioconjug Chem. (2010) 21:1023-5. doi: 10.1021/bc100178z

74. Lovell JF, Jin $\mathrm{H}, \mathrm{Ng} \mathrm{KK}$, Zheng G. Programmed nanoparticle aggregation using molecular beacons. Angew Chem Int Ed Engl. (2010) 49:7917-9. doi: 10.1002/anie.201003846

75. Nesterova IV, Erdem SS, Pakhomov S, Hammer RP, Soper SA. Phthalocyanine dimerization-based molecular beacons using near-IR fluorescence. J Am Chem Soc. (2009) 131:2432-3. doi: 10.1021/ja8088247

76. Campo MA, Gabriel D, Kucera P, Gurny R, Lange N. Polymeric photosensitizer prodrugs for photodynamic therapy. Photochem Photobiol. (2007) 83:958-65. doi: 10.1111/j.1751-1097.2007.00090.x

77. Gabriel D, Campo MA, Gurny R, Lange N. Tailoring protease-sensitive photodynamic agents to specific disease-associated enzymes. Bioconjug Chem. (2007) 18:1070-7. doi: 10.1021/bc060321l

78. Mawn TM, Popov AV, Beardsley NJ, Stefflova K, Milkevitch M, Zheng G, et al. In Vivo detection of phospholipase c by enzyme-activated near-infrared probes. Bioconjug Chem. (2011) 22:2434-43. doi: 10.1021/bc200242v

79. Chen J, Stefflova K, Niedre MJ, Wilson BC, Chance B, Glickson JD, et al. Protease-triggered photosensitizing beacon based on singlet oxygen quenching and activation. J Am Chem Soc. (2004) 126:11450-1. doi: $10.1021 / \mathrm{ja} 047392 \mathrm{k}$

80. Fujita N, Nagahashi A, Nagashima K, Rokudai S, Tsuruo T. Acceleration of apoptotic cell death after the cleavage of Bcl-XL protein by caspase-3-like proteases. Oncogene (1998) 17:1295-304. doi: 10.1038/sj.onc.1202065

81. Gust D, Moore TA, Moore AL, Jori G, Reddi E. The photochemistry of carotenoids. Some photosynthetic and photomedical aspects. Ann NY Acad Sci. (1993) 691:32-47. doi: 10.1111/j.1749-6632.1993.tb26155.x

82. Lovell JF, Chan MW, Qi Q, Chen J, Zheng G. Porphyrin FRET acceptors for apoptosis induction and monitoring. J Am Chem Soc. (2011) 133:18580-2. doi: $10.1021 /$ ja2083569

83. Chen J, Liu TWB, Lo P-C, Wilson BC, Zheng G. "Zipper” molecular beacons: a generalized strategy to optimize the performance of activatable protease probes. Bioconjug Chem. (2009) 20:1836-42. doi: 10.1021/bc900207k

84. Luo D, Carter KA, Lovell JF. Nanomedical engineering: shaping future nanomedicines. Wiley Interdiscip Rev Nanomed Nanobiotechnol. (2014) 7:169-88. doi: 10.1002/wnan.1315

85. Bechet D, Couleaud P, Frochot C, Viriot M-L, Guillemin F, Barberi-Heyob M. Nanoparticles as vehicles for delivery of photodynamic therapy agents. Trends Biotechnol. (2008) 26:612-21. doi: 10.1016/j.tibtech.2008.07.007

86. Svenson S, Tomalia DA. Dendrimers in biomedical applicationsreflections on the field. Adv Drug Deliv Rev. (2012) 64:102-15. doi: 10.1016/j.addr.2012.09.030

87. Gajbhiye V, Palanirajan VK, Tekade RK, Jain NK. Dendrimers as therapeutic agents: a systematic review. J Pharm Pharmacol. (2009) 61:989-1003. doi: 10.1211/jpp.61.08.0002

88. Jin R-H, Aida T, Inoue S. 'Caged' porphyrin: the first dendritic molecule having a core photochemical functionality. J Chem Soc Chem Commun. (1993) 1993:1260-2. doi: 10.1039/C39930001260

89. Cheng L, Wang C, Feng L, Yang K, Liu Z. Functional nanomaterials for phototherapies of cancer. Chem Rev. (2014) 114:10869-939. doi: $10.1021 / \mathrm{cr} 400532 \mathrm{z}$

90. Li W-S, Aida T. Dendrimer porphyrins and phthalocyanines. Chem Rev. (2009) 109:6047-76. doi: 10.1021/cr900186c

91. Jin CS, Zheng G. Liposomal nanostructures for photosensitizer delivery. Lasers Surg Med. (2011) 43:734-48. doi: 10.1002/1sm.21101

92. Jesorka A, Orwar O. Liposomes: technologies and analytical applications. Annu Rev Anal Chem. (2008) 1:801-32. doi: 10.1146/annurev.anchem.1.031207.112747

93. Immordino ML, Dosio F, Cattel L. Stealth liposomes: review of the basic science, rationale, and clinical applications, existing and potential. Int J Nanomedicine. (2006) 1:297.

94. Derycke ASL, de Witte PAM. Liposomes for photodynamic therapy. $A d v$ Drug Deliv Rev. (2004) 56:17-30. doi: 10.1016/j.addr.2003.07.014
95. Torchilin VP. Recent advances with liposomes as pharmaceutical carriers Nat Rev Drug Discov. (2005) 4:145-60. doi: 10.1038/nrd1632

96. Ghoroghchian PP, Frail PR, Susumu K, Blessington D, Brannan AK, Bates FS, et al. Near-infrared-emissive polymersomes: Self-assembled soft matter for in vivo optical imaging. Proc Natl Acad Sci USA. (2005) 102:2922-7. doi: 10.1073/pnas.0409394102

97. Anikeeva N, Sykulev Y, Delikatny EJ, Popov AV. Core-based lipid nanoparticles as a nanoplatform for delivery of near-infrared fluorescent imaging agents. Am J Nucl Med Mol Imaging. (2014) 4:507-24.

98. Huynh E, Zheng G. Porphysome nanotechnology: a paradigm shift in lipid-based supramolecular structures. Nano Today (2014) 9:212-22. doi: 10.1016/j.nantod.2014.04.012

99. Hsu C-Y, Nieh M-P, Lai P-S. Facile self-assembly of porphyrin-embedded polymeric vesicles for theranostic applications. Chem Commun. (Camb.) (2012) 48:9343-5. doi: 10.1039/c2cc33851c

100. Lee JH, Shao S, Cheng KT, Lovell JF, Paik CH. 99mTc-labeled porphyrin-lipid nanovesicles. J Liposome Res. (2014). doi: 10.3109/08982104.2014.932379. [Epub ahead of print].

101. Jin CS, Lovell JF, Chen J, Zheng G. Ablation of hypoxic tumors with dose-equivalent photothermal, but not photodynamic, therapy using a nanostructured porphyrin assembly. ACS Nano (2013) 7:2541-50. doi: $10.1021 / \mathrm{nn} 3058642$

102. Liang X, Li X, Yue X, Dai Z. Conjugation of porphyrin to nanohybrid cerasomes for photodynamic diagnosis and therapy of cancer. Angew Chem. (2011) 123:11826-31. doi: 10.1002/ange.201103557

103. Farhadi A, Roxin A, Wilson BC, Zheng G. Nano-enabled SERS reporting photosensitizers. Theranostics (2015) 5:469-76. doi: 10.7150/thno.10694

104. Tam NCM, McVeigh PZ, MacDonald TD, Farhadi A, Wilson BC, Zheng G. Porphyrin-lipid stabilized gold nanoparticles for surface enhanced raman scattering based imaging. Bioconjug Chem. (2012) 23:1726-30. doi: $10.1021 / \mathrm{bc} 300214 \mathrm{z}$

105. MacDonald TD, Liu TW, Zheng G. An MRI-sensitive, non-photobleachable porphysome photothermal agent. Angew Chem. (2014) 126:7076-9. doi: 10.1002/ange.201400133

106. Liu TW, MacDonald TD, Shi J, Wilson BC, Zheng G. Intrinsically copper64-labeled organic nanoparticles as radiotracers. Angew Chem Int Ed Engl. (2012) 51:13128-31. doi: 10.1002/anie.201206939

107. Auguste DT, Furman K, Wong A, Fuller J, Armes SP, Deming TJ, et al. Triggered release of siRNA from poly(ethylene glycol)-protected, pH-dependent liposomes. J Control Release. (2008) 130:266-74. doi: 10.1016/j.jconrel.2008.06.004

108. Auguste DT, Armes SP, Brzezinska KR, Deming TJ, Kohn J, Prud'homme RK. pH triggered release of protective poly(ethylene glycol)-b-polycation copolymers from liposomes. Biomaterials (2006) 27:2599-608. doi: 10.1016/j.biomaterials.2005.08.036

109. Kim MS, Lee DS. Biodegradable and $\mathrm{pH}$-sensitive polymersome with tuning permeable membrane for drug delivery carrier. Chem Commun. (Camb.) (2010) 46:4481-3. doi: 10.1039/c001500h

110. Tan ML, Choong PFM, Dass CR. Recent developments in liposomes, microparticles and nanoparticles for protein and peptide drug delivery. Peptides (2010) 31:184-93. doi: 10.1016/j.peptides.2009.10.002

111. Kono K, Nakashima S, Kokuryo D, Aoki I, Shimomoto H, Aoshima S, et al. Multi-functional liposomes having temperature-triggered release and magnetic resonance imaging for tumor-specific chemotherapy. Biomaterials (2011) 32:1387-95. doi: 10.1016/j.biomaterials.2010.10.050

112. Lovell JF, Jin CS, Huynh E, MacDonald TD, Cao W, Zheng G. Enzymatic regioselection for the synthesis and biodegradation of porphysome nanovesicles. Angew Chem. (2012) 124:2479-83. doi: 10.1002/ange.201 108280

113. Jin CS, Cui L, Wang F, Chen J, Zheng G. Targeting-triggered porphysome nanostructure disruption for activatable photodynamic therapy. Adv Healthc Mater. (2014) 3:1240-9. doi: 10.1002/adhm.201300651

114. Carter KA, Shao S, Hoopes MI, Luo D, Ahsan B, Grigoryants VM, et al. Porphyrin-phospholipid liposomes permeabilized by near-infrared light. Nat Commun. (2014) 5:3546. doi: 10.1038/ncomms4546

115. Huynh E, Lovell JF, Fobel R, Zheng G. Optically controlled pore formation in self-sealing giant porphyrin vesicles. Small (2014) 10:1184-93. doi: $10.1002 /$ smll.201302424 
116. Rieffel J, Chen F, Kim J, Chen G, Shao W, Shao S, et al. Hexamodal imaging with porphyrin-phospholipid-coated upconversion nanoparticles. $A d v$ Mater (2015) 27:1785-90. doi: 10.1002/adma.201404739

117. Ng KK, Lovell JF, Vedadi A, Hajian T, Zheng G. Self-assembled porphyrin nanodiscs with structure-dependent activation for phototherapy and photodiagnostic applications. ACS Nano (2013) 7:3484-90. doi: $10.1021 / \mathrm{nn} 400418 \mathrm{y}$

118. Trewyn BG, Giri S, Slowing II, Lin VSY. Mesoporous silica nanoparticle based controlled release, drug delivery, and biosensor systems. Chem Commun. (Camb.) (2007) 2007:3236-45. doi: 10.1039/B701744H

119. He Q, Shi J. Mesoporous silica nanoparticle based nano drug delivery systems: synthesis, controlled drug release and delivery, pharmacokinetics and biocompatibility. J Mater Chem. (2011) 21:5845-55. doi: 10.1039/C0JM03851B

120. Slowing II, Vivero-Escoto JL, Trewyn BG, Lin VSY. Mesoporous silica nanoparticles: structural design and applications. J Mater Chem. (2010) 20:7924-37. doi: 10.1039/C0JM00554A

121. Rosenholm JM, Sahlgren C, Lindén M. Towards multifunctional, targeted drug delivery systems using mesoporous silica nanoparticles - opportunities \&amp; challenges. Nanoscale (2010) 2:1870-83. doi: 10.1039/c0nr00156b

122. Lee C-H, Cheng S-H, Wang Y-J, Chen Y-C, Chen N-T, Souris J, et al. Nearinfrared mesoporous silica nanoparticles for optical imaging: characterization and in vivo biodistribution. Adv Funct Mater. (2009) 19:215-22. doi: 10.1002/adfm.200800753

123. Hsiao J-K, Tsai C-P, Chung T-H, Hung Y, Yao M, Liu H-M, et al. Mesoporous silica nanoparticles as a delivery system of gadolinium for effective human stem cell tracking. Small (2008) 4:1445-52. doi: 10.1002/smll.200701316

124. Liong M, Lu J, Kovochich M, Xia T, Ruehm SG, Nel AE, et al. Multifunctional inorganic nanoparticles for imaging, targeting, and drug delivery. ACS Nano (2008) 2:889-96. doi: 10.1021/nn800072t

125. Taylor KML, Kim JS, Rieter WJ, An H, Lin W, Lin W. Mesoporous silica nanospheres as highly efficient mri contrast agents. J Am Chem Soc. (2008) 130:2154-5. doi: 10.1021/ja710193c

126. Vivero-Escoto JL, Slowing II, Trewyn BG, Lin VSY. Mesoporous silica nanoparticles for intracellular controlled drug delivery. Small (2010) 6:1952-67. doi: 10.1002/smll.200901789

127. Brevet D, Gary-Bobo M, Raehm L, Richeter S, Hocine O, Amro K, et al. Mannose-targeted mesoporous silica nanoparticles for photodynamic therapy. Chem Commun. (Camb.) (2009) 2009:1475-7. doi: 10.1039/b900427k

128. Couleaud P, Morosini V, Frochot C, Richeter S, Raehm L, Durand J-O. Silica-based nanoparticles for photodynamic therapy applications. Nanoscale (2010) 2:1083-95. doi: 10.1039/C0NR00096E

129. Hocine O, Gary-Bobo M, Brevet D, Maynadier M, Fontanel S, Raehm L, et al. Silicalites and mesoporous silica nanoparticles for photodynamic therapy. Int J Pharm. (2010) 402:221-30. doi: 10.1016/j.ijpharm.2010.10.004

130. Zhao T, Wu H, Yao SQ, Xu Q-H, Xu GQ. Nanocomposites containing gold nanorods and porphyrin-doped mesoporous silica with dual capability of two-photon imaging and photosensitization. Langmuir (2010) 26:14937-42. doi: 10.1021/la102556u

131. Gary-Bobo M, Hocine O, Brevet D, Maynadier M, Raehm L, Richeter S, et al. Cancer therapy improvement with mesoporous silica nanoparticles combining targeting, drug delivery and PDT. Int J Pharm. (2012) 423:509-15. doi: 10.1016/j.ijpharm.2011.11.045

132. Gary-Bobo M, Mir Y, Rouxel C, Brevet D, Hocine O, Maynadier M, et al. Multifunctionalized mesoporous silica nanoparticles for the in vitro treatment of retinoblastoma: drug delivery, one and two-photon photodynamic therapy. Int J Pharm. (2012) 432:99-104. doi: 10.1016/j.ijpharm.2012.04.056

133. Secret E, Maynadier M, Gallud A, Gary-Bobo M, Chaix A, Belamie E, et al. Anionic porphyrin-grafted porous silicon nanoparticles for photodynamic therapy. Chem Commun. (Camb.) (2013) 49:4202-4. doi: $10.1039 / \mathrm{c} 3 \mathrm{cc} 38837 \mathrm{a}$

134. Zhao B, Yin J-J, Bilski PJ, Chignell CF, Roberts JE, He Y-Y. Enhanced photodynamic efficacy towards melanoma cells by encapsulation of Pc4 in silica nanoparticles. Toxicol Appl Pharmacol. (2009) 241:163-72. doi: 10.1016/j.taap.2009.08.010

135. Qian HS, Guo HC, Ho PC-L, Mahendran R, Zhang Y. Mesoporous-silicacoated up-conversion fluorescent nanoparticles for photodynamic therapy. Small (2009) 5:2285-90. doi: 10.1002/smll.200900692
136. Tu J, Wang T, Shi W, Wu G, Tian X, Wang Y, et al. Multifunctional ZnPcloaded mesoporous silica nanoparticles for enhancement of photodynamic therapy efficacy by endolysosomal escape. Biomaterials (2012) 33:7903-14. doi: 10.1016/j.biomaterials.2012.07.025

137. Wang T, Zhang L, Su Z, Wang C, Liao Y, Fu Q. Multifunctional hollow mesoporous silica nanocages for cancer cell detection and the combined chemotherapy and photodynamic therapy. ACS Appl Mater Interfaces. (2011) 3:2479-86. doi: 10.1021/am200364e

138. Nguyen KT, West JL. Photopolymerizable hydrogels for tissue engineering applications. Biomaterials (2002) 23:4307-14. doi: 10.1016/S01429612(02)00175-8

139. Van Vlierberghe S, Dubruel P, Schacht E. Biopolymer-based hydrogels as scaffolds for tissue engineering applications: a review. Biomacromolecules (2011) 12:1387-408. doi: 10.1021/bm200083n

140. Balakrishnan B, Banerjee R. Biopolymer-based hydrogels for cartilage tissue engineering. Chem Rev. (2011) 111:4453-74. doi: 10.1021/cr100123h

141. Park H, Park K, Shalaby WSW. Biodegradable Hydrogels for Drug Delivery. Technomic Publishing Company, Inc. (1993). 272 p.

142. Brandl F, Kastner F, Gschwind RM, Blunk T, Teßmar J, Göpferich A. Hydrogel-based drug delivery systems: comparison of drug diffusivity and release kinetics. J Control Release. (2010) 142:221-8. doi: 10.1016/j.jconrel.2009.10.030

143. Hah HJ, Kim G, Lee Y-EK, Orringer DA, Sagher O, Philbert MA, et al. Methylene blue-conjugated hydrogel nanoparticles and tumor-cell targeted photodynamic therapy. Macromol Biosci. (2011) 11:90-9. doi: 10.1002/mabi.201000231

144. Donnelly RF, Cassidy CM, Loughlin RG, Brown A, Tunney MM, Jenkins MG, et al. Delivery of methylene blue and meso-tetra (N-methyl-4-pyridyl) porphine tetra tosylate from cross-linked poly(vinyl alcohol) hydrogels: a potential means of photodynamic therapy of infected wounds. J Photochem Photobiol B. (2009) 96:223-31. doi: 10.1016/j.jphotobiol.2009.06.010

145. Fallows SJ, Garland MJ, Cassidy CM, Tunney MM, Singh TRR, Donnelly RF. Electrically-responsive anti-adherent hydrogels for photodynamic antimicrobial chemotherapy. J Photochem Photobiol B. (2012) 114:61-72. doi: 10.1016/j.jphotobiol.2012.05.011

146. Bonnett R, Buckley DG, Burrow T, Galia ABB, Saville B, Songca SP. Photobactericidal materials based on porphyrins and phthalocyanines. J Mater Chem. (1993) 3:323-4. doi: 10.1039/JM99303 00323

147. Parsons C, McCoy CP, Gorman SP, Jones DS, Bell SEJ, Brady C, et al. Antiinfective photodynamic biomaterials for the prevention of intraocular lensassociated infectious endophthalmitis. Biomaterials (2009) 30:597-602. doi: 10.1016/j.biomaterials.2008.10.015

148. Lv F, Mao L, Liu T. Thermosensitive porphyrin-incorporated hydrogel with four-arm PEG-PCL copolymer: preparation, characterization and fluorescence imaging in vivo. Mater Sci Eng C. (2014) 43:221-30. doi: 10.1016/j.msec.2014.07.019

149. Jang B, Park J-Y, Tung C-H, Kim I-H, Choi Y. Gold nanorodphotosensitizer complex for near-infrared fluorescence imaging and photodynamic/photothermal therapy in vivo. ACS Nano (2011) 5:1086-94. doi: $10.1021 / \mathrm{nn} 102722 \mathrm{z}$

150. Camerin M, Rello-Varona S, Villanueva A, Rodgers MAJ, Jori G. Metallonaphthalocyanines as photothermal sensitisers for experimental tumours: in vitro and in vivo studies. Lasers Surg Med. (2009) 41:665-73. doi: $10.1002 / \mathrm{lsm} .20846$

151. Lim C-K, Shin J, Lee Y-D, Kim J, Oh KS, Yuk SH, et al. Phthalocyanineaggregated polymeric nanoparticles as tumor-homing near-infrared absorbers for photothermal therapy of cancer. Theranostics (2012) 2:871. doi: 10.7150/thno.4133

152. Pawlicki M, Collins HA, Denning RG, Anderson HL. Two-photon absorption and the design of two-photon dyes. Angew Chem Int Ed Engl. (2009) 48:3244-66. doi: 10.1002/anie.200805257

153. Kuimova MK, Collins HA, Balaz M, Dahlstedt E, Levitt JA, Sergent N, et al. Photophysical properties and intracellular imaging of water-soluble porphyrin dimers for two-photon excited photodynamic therapy. Org Biomol Chem. (2009) 7:889-96. doi: 10.1039/B814791D

154. Balaz M, Collins HA, Dahlstedt E, Anderson HL. Synthesis of hydrophilic conjugated porphyrin dimers for one-photon and two-photon 
photodynamic therapy at NIR wavelengths. Org Biomol Chem. (2009) 7:874-88. doi: 10.1039/B814789B

155. Odom SA, Webster S, Padilha LA, Peceli D, Hu H, Nootz G, et al. Synthesis and two-photon spectrum of a bis(Porphyrin)-substituted squaraine. J Am Chem Soc. (2009) 131:7510-1. doi: 10.1021/ja $901244 \mathrm{e}$

156. Wu C, Xu Q-H. Enhanced one- and two-photon excitation emission of a porphyrin photosensitizer by FRET from a conjugated polyelectrolyte. Macromol Rapid Commun. (2009) 30:504-8. doi: 10.1002/marc.2008 00655

157. Poon C-T, Chan P-S, Man C, Jiang F-L, Wong RNS, Mak N-K, et al. An amphiphilic ruthenium(II)-polypyridyl appended porphyrin as potential bifunctional two-photon tumor-imaging and photodynamic therapeutic agent. J Inorg Biochem. (2010) 104:62-70. doi: 10.1016/j.jinorgbio.2009.10.004

158. Secret E, Maynadier M, Gallud A, Chaix A, Bouffard E, Gary-Bobo M, et al. Two-photon excitation of porphyrin-functionalized porous silicon nanoparticles for photodynamic therapy. Adv Mater. (2014) 26:7643-8. doi: 10.1002/adma.201403415

159. Bullous AJ, Alonso CMA, Boyle RW. Photosensitiser-antibody conjugates for photodynamic therapy. Photochem Photobiol Sci. (2011) 10:721-50. doi: 10.1039/COPP00266F

160. Mir Y, Elrington SA, Hasan T. A new nanoconstruct for epidermal growth factor receptor-targeted photo-immunotherapy of ovarian cancer. Nanomedicine (2013) 9:1114-22. doi: 10.1016/j.nano.2013. 02.005

161. Patel H, Mick R, Finlay J, Zhu TC, Rickter E, Cengel KA, et al. Motexafin lutetium-photodynamic therapy of prostate cancer: short and long term effects on PSA. Clin Cancer Res. (2008) 14:4869. doi: 10.1158/10780432.CCR-08-0317

162. Alonso CM, Palumbo A, Bullous AJ, Pretto F, Neri D, Boyle RW. Sitespecific and stoichiometric conjugation of cationic porphyrins to antiangiogenic monoclonal antibodies. Bioconjug Chem. (2010) 21:302-13. doi: $10.1021 / \mathrm{bc} 9003537$

163. Mew D, Wat C-K, Towers G, Levy J. Photoimmunotherapy: treatment of animal tumors with tumor-specific monoclonal antibody-hematoporphyrin conjugates. J Immunol. (1983) 130:1473-7.

164. Goff BA, Bamberg M, Hasan T. Photoimmunotherapy of human ovarian carcinoma cells ex vivo. Cancer Res. (1991) 51: $4762-7$.

165. Hudson R, Carcenac M, Smith K, Madden L, Clarke OJ, Pelegrin A, et al. The development and characterisation of porphyrin isothiocyanatemonoclonal antibody conjugates for photoimmunotherapy. Br J Cancer. (2005) 92:1442-9. doi: 10.1038/sj.bjc.6602517
166. Mitsunaga M, Ogawa M, Kosaka N, Rosenblum LT, Choyke PL, Kobayashi H. Cancer cell-selective in vivo near infrared photoimmunotherapy targeting specific membrane molecules. Nat Med. (2011) 17:1685-91. doi: $10.1038 / \mathrm{nm} .2554$

167. Mitsunaga M, Nakajima T, Sano K, Choyke PL, Kobayashi H. Near-infrared theranostic photoimmunotherapy (PIT): repeated exposure of light enhances the effect of immunoconjugate. Bioconjug Chem. (2012) 23:604-9. doi: $10.1021 / \mathrm{bc} 200648 \mathrm{~m}$

168. Sano K, Nakajima T, Choyke PL, Kobayashi H. Markedly enhanced permeability and retention effects induced by photo-immunotherapy of tumors. ACS Nano (2012) 7:717-24. doi: 10.1021/nn305011p

169. Sato K, Watanabe R, Hanaoka H, Harada T, Nakajima T, Kim I, et al. Photoimmunotherapy: comparative effectiveness of two monoclonal antibodies targeting the epidermal growth factor receptor. Mol Oncol. (2014) 8:620-32. doi: 10.1016/j.molonc.2014.01.006

170. Sato K, Hanaoka H, Watanabe R, Nakajima T, Choyke PL, Kobayashi H. Near infrared photoimmunotherapy in the treatment of disseminated peritoneal ovarian cancer. Mol Cancer Ther. (2015) 14:141-50. doi: 10.1158/15357163.MCT-14-0658

171. Chen B, Pogue BW, Hoopes PJ, Hasan T. Vascular and cellular targeting for photodynamic therapy. Crit Rev Eukaryot Gene Expr. (2006) 16:279-306. doi: 10.1615/CritRevEukarGeneExpr.v16.i4.10

172. Molema G. Tumor vasculature directed drug targeting: applying new technologies and knowledge to the development of clinically relevant therapies. Pharm Res. (2002) 19:1251-8. doi: 10.1023/A:1020312220968

173. Brandis A, Mazor O, Neumark E, Rosenbach-Belkin V, Salomon Y, Scherz A. Novel water-soluble bacteriochlorophyll derivatives for vascular-targeted photodynamic therapy: synthesis, solubility, phototoxicity and the effect of serum proteins. Photochem Photobiol. (2005) 81:983-92. doi: 10.1111/j.17511097.2005.tb01473.x

174. Reddy GR, Bhojani MS, McConville P, Moody J, Moffat BA, Hall DE, et al. Vascular targeted nanoparticles for imaging and treatment of brain tumors. Clin Cancer Res. (2006) 12:6677-86. doi: 10.1158/1078-0432

Conflict of Interest Statement: The authors declare that the research was conducted in the absence of any commercial or financial relationships that could be construed as a potential conflict of interest.

Copyright $\odot 2015$ Huang, Song, Rieffel and Lovell. This is an open-access article distributed under the terms of the Creative Commons Attribution License (CC BY). The use, distribution or reproduction in other forums is permitted, provided the original author(s) or licensor are credited and that the original publication in this journal is cited, in accordance with accepted academic practice. No use, distribution or reproduction is permitted which does not comply with these terms. 